Document downloaded from:

http://hdl.handle.net/10251/65358

This paper must be cited as:

Jiménez Bello, MA.; Castel, JR.; Testi, L.; Intrigliolo Molina, DS. (2015). Assessment of a Remote Sensing Energy Balance Methodology (SEBAL) Using Different Interpolation Methods to Determine Evapotranspiration in a Citrus Orchard. IEEE Journal of Selected Topics in Applied Earth Observations and Remote Sensing. 8(4):1465-1477. doi:10.1109/JSTARS.2015.2418817.

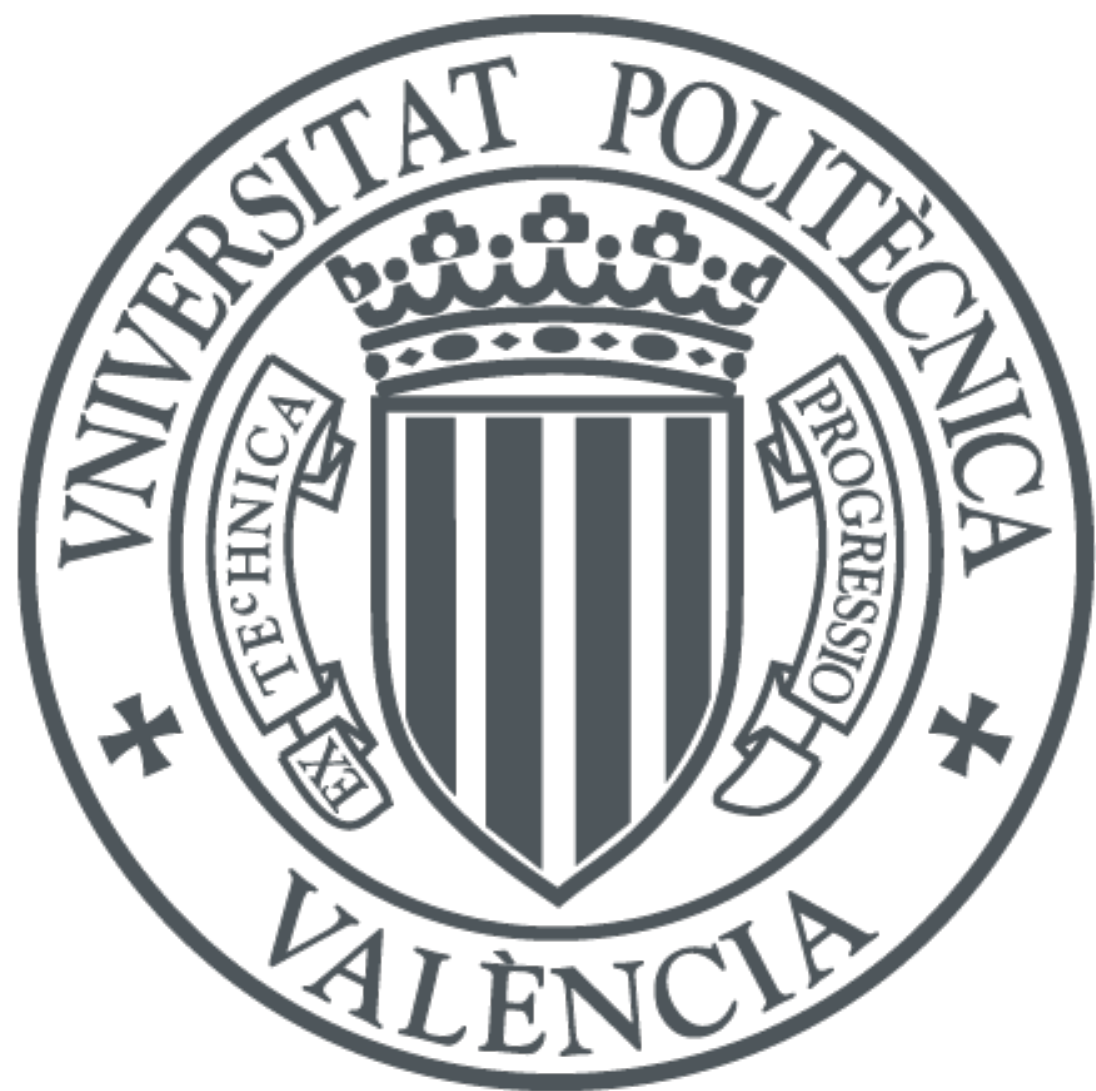

The final publication is available at

http://dx.doi.org/10.1109/JSTARS.2015.2418817

Copyright Institute of Electrical and Electronics Engineers (IEEE)

Additional Information

"(c) 2015 IEEE. Personal use of this material is permitted. Permission from IEEE must be obtained for all other users, including reprinting/ republishing this material for advertising or promotional purposes, creating new collective works for resale or redistribution to servers or lists, or reuse of any copyrighted components of this work in other works." 


\section{Assessment of a remote sensing energy balance methodology (SEBAL) using different interpolation methods to determine evapotranspiration in a citrus orchard}

A surface energy balance model (SEBAL) for estimating evapotranspiration (ET) has been parameterized and tested in a 400 ha drip irrigated citrus orchard. Simultaneously, during three growing seasons, energy fluxes were measured using Eddy Covariance. Instantaneous fluxes obtained with SEBAL using 10 images from Landsat-5 were compared with the measured fluxes. The Perrier function was the best method for properly estimating the roughness momentum length for discontinuous canopies, as in citrus orchards. Crop height was estimated using LIDAR data. In general, SEBAL performed well for net radiation estimation but failed in soil heat flux estimation. Latent heat estimations from the SEBAL model had a relative Root Mean Square Error (rRMSE) of 0.06 when compared with measurements obtained by eddy covariance. Three procedures were tested for up-scaling the instantaneous ET estimates from SEBAL to daily ET values: 1) assuming the fraction between the actual ET and the reference evapotranspiration is constant throughout the day, 2) using actual local crop coefficient curves, and 3) using an up-scaling factor where the fraction of hourly ET to daily ET equals the ratio of hourly to daily global solar radiation. This last method gave acceptable results for daily ET estimations (rRMSE $=0.09)$ and for15-days ET $(\mathrm{rRMSE}=0.19)$, and its main advantage is that no local data are required. It is concluded that the SEBAL methodology can be successfully applied for determining actual ET, even in discontinuous citrus canopies. However, additional parameterizations of momentum roughness length were needed in order to obtain reliable ET determinations. 


\section{Introduction}

Evapotranspiration is a key component of hydrological balance. In addition, water use in tree orchards is the main variable to be determined for precise and efficient water management of irrigated lands. Several tools and models for estimating evapotranspiration in tree orchards have been proposed (Rana and Katerji 2000). Among them, the most widely used approach is that proposed by FAO (Allen et al. 1998), which takes into account climatic variables included in the reference evapotranspiration $\left(\mathrm{ET}_{\mathrm{o}}\right)$, as well as the crop type and its characteristics, included in a single crop coefficient $\left(\mathrm{K}_{\mathrm{c}}\right)$. The estimated crop evapotranspiration $\left(\mathrm{ET}_{\mathrm{c}}\right)$ is calculated as the product of $\mathrm{ET}_{\mathrm{o}}$ multiplied by $\mathrm{K}_{\mathrm{c}}$. However, there is evidence that in tall and discontinuous canopies, such as citrus orchards, with a high degree of coupling to the environment, $\mathrm{K}_{\mathrm{c}}$ may change depending on local environmental conditions (Annandale and Stockle 1994; Ballester et al. 2013) and the vegetation amount, height and density (Allen and Pereira 2009). It is therefore important to determine the possibility of using other alternatives for calculating the actual orchard $\mathrm{ET}_{\mathrm{c}}$ rate. Remotely sensed data obtained from different sensors have been used to calculate actual evapotranspiration (ET) by means of different operational models (Liang et al. 2010; Kalma et al. 2008). Two general types of remote sensing approaches for estimating ET have been successfully applied in agricultural and hydrological water use studies as indicated by Gonzalez-Dugo et al. (2009). One of these approaches consists in estimating crop coefficients from remotely sensed vegetation indices derived from surface reflectance data. These methods produce $K_{c}$ maps that reflect the crop growth stage and, with the support of $\mathrm{ET}_{\mathrm{o}}$ data obtained from meteorological stations, crop water requirements can be estimated. Several studies have related the Normalized Differenced Vegetation Index 
(NDVI) or the Soil Adjusted Vegetation Index with $\mathrm{K}_{\mathrm{c}}$ (Jayanthi et al. 2007;GonzálezDugo and Mateos 2008; Mateos et al. 2013). The main drawback of these techniques is that they rely on empirical, site-specific relationships between an index of vegetation (e.g. ground cover, plant size, leaf area index, etc.) and $\mathrm{K}_{\mathrm{c}}$, which are not always available for all agricultural land-uses. In addition, these empirical relationships are most often obtained under base-line conditions, with no soil water limitations. To overcome this limitation Stanghellini et al. (1990) proposed that since the ratio of crop evapotranspiration to reference evaporation is not constant, when knowledge of a number of crop-specific parameters is available, a "theoretical" transpiration formula is likely to deliver better estimates of crop water requirement than calculations based on crop coefficients. Nevertheless this method has to be tested and validated with actual ET measures.

The second approach for determining ET via remote sensing is using models that calculate the latent heat as a residual of the surface energy balance (SEB). Bastiaanssen et al. (1998) developed Surface Energy Balance Algorithms for Land (SEBAL). This is a satellite-based image-processing algorithm calibrated using inverse modeling at extreme conditions to develop image specific estimations of the sensible heat flux component of the surface energy balance and to remove systematic biases in estimates of net radiation, soil heat flux, radiometric temperature and aerodynamic resistance. The innovative component of SEBAL is that the energy balance modeling uses a nearsurface temperature gradient which is indexed to radiometric surface temperature, thereby eliminating the need for absolute surface temperature calibration, which has been a major impediment to operational satellite ET (Kustas and Norman 1996). The application of the SEB models requires the use of sensors having a thermal band. However, these satellite sensors have coarse spatial resolution for irrigation 
management. As an example, the lowest thermal spatial resolution for Landsat TM5 is $120 \mathrm{~m}$ and for TM7 is $60 \mathrm{~m}$ (Kustas et al. 2004). Landsat 8, launched in 2013, has a 100 $\mathrm{m}$ resolution. For all of these platforms, final products can be re-sampled to $30 \mathrm{~m}$. This pixel size makes impossible the accurate separation of canopy temperature from the sunlit and shaded soil background (Berni et al. 2009), so final temperature is the result of all the elements present in the pixel. In addition, when satellite passes are infrequent, the applicability of remote sensing-based estimates of ET is hampered by the fact that data is only available for each satellite revisit time if cloudless conditions allow the use of the images.

Another limitation of the SEB approaches is that the instantaneous ET (ET inst $_{\text {) obtained }}$ at the time of the satellite pass has to be extrapolated to daily values in order to be useful, both for irrigation scheduling purposes at farm level and for general water resource management at the irrigation district or watershed level. As González-Dugo et al. (2009) described, daily scaling is generally performed by assuming the conservation of a scaling factor determined at the snapshot time, such as the evaporative fraction (Crago and Brutsaert 1996) or the ratio of ET to $\mathrm{ET}_{\mathrm{o}}$ (Allen et al. 2007a). These assumptions have been applied in sparse woody canopies such as pecan (Samani et al. 2009) and olive (Santos et al. 2012). However, Ferguson et al. (2010) identified the constant $\mathrm{ET}$ to $\mathrm{ET}_{\mathrm{o}}$ ratio approach as a major source of uncertainty in the remote sensing based energy estimates, particularly for agricultural systems different than homogeneous grasslands where a low degree of canopy coupling with the surrounding atmosphere exists (Jarvis 1985). This is the case for citrus trees, an evergreen perennial crop that regulates stomatal closure under changing environmental conditions (mostly air vapor pressure deficit), therefore resulting in $\mathrm{K}_{\mathrm{c}}$ variability along the day (Kriedemann 1986). 
There are few studies conducted on the calculation of ET in citrus. Minacapilli et al. (2009) compared two SEB approaches, the SEBAL model and the TSEB (Two-Source Energy Balance model; Norman et al, 1995) to estimate the actual ET from typical spatially sparse Mediterranean vegetation (with olives, citrus and vineyards). However, ET extrapolation was not treated further than for a one day period, given that the imagery used was obtained by an airborne sensor flying during a single day. Consoli et al. (2006a) used high spatial resolution images from the Ikonos satellite to estimate $\mathrm{K}_{\mathrm{c}}$ from derived Leaf Area Index (LAI) using the methodology proposed by Stanghellini et al. (1990). LAI estimation was validated with field measures, but ET estimations were not compared with an independent ET determination. Mateos et al. (2013) used the dual crop coefficient and the synthetic crop coefficient approaches with Landsat 5 images in a mandarin orchard. ET estimations were compared with eddy covariance data from an experiment conducted by Villalobos et al. (2009) and were reasonably well estimated. In this work, the Surface Energy Balanced Algorithm (SEBAL, Bastiaansen et al., 1998) has been applied to a citrus orchard. Sensible heat (H) and latent heat (LE) fluxes obtained from 10 dates from Landsat Tm5 images were compared with data supplied by an Eddy Covariance flux tower. Three methods were tested to extrapolate instantaneous ET to daily and to 15 -day periods.

\section{Methodology}

\subsection{Experimental field}

The experimental field was a commercial farm of 400 ha planted with Hernandina mandarin (Citrus clementina, Hort ex Tan) grafted on Carrizo Citrange (Citrus sinensis, Osb. 3 Poncirustrifoliata, Raf.) at a spacing of $6 \mathrm{~m}$ by $3 \mathrm{~m}$, located in Chiva, Valencia, 
eastern Spain $\left(39^{\circ} 27^{\prime} 15^{\prime \prime} \mathrm{N}, 0^{\circ} 33^{\prime} 32^{\prime \prime} \mathrm{W}\right) ; 105 \mathrm{~m}$ above sea level, wind regime typically dominated by sea breezes and distance to sea of $11 \mathrm{Km}$. Fig 1 shows the location of the study area.The plot was flat and well drip irrigated throughout the growing season with 6 emitters of $41 \mathrm{~h}^{-1}$ per tree, arranged in two lines. Trees were mature, with an average height of $2.80 \mathrm{~m}$ and the area shaded by the canopy was $66 \%$ of the allotted spacing. Soil was of sandy loam texture.

The three seasons studied showed the classical climatic Mediterranean characteristics with the more intense rainy period concentrated in autumn, especially in 2008 and 2009 (Fig 2). During the late spring and summer time, $\mathrm{ET}_{\mathrm{o}}$ is considerably higher than precipitation. Irrigation was applied to reach the full crop evapotranspiration, hence no soil water limitations occurred during the experiment. Table 1 shows the $\mathrm{ET}_{\mathrm{o}}$, the $\mathrm{ET}_{\mathrm{c}}$ calculated from the Eddy flux tower (see below), the precipitation and the irrigation volumes applied for each of the entire 3 seasons.

\subsection{Eddy covariance measurements}

The eddy covariance equipment was installed at $6.5 \mathrm{~m}$ height on a scaffold, placed in the plot center. The estimated radius of the flux footprint was $485 \mathrm{~m}$. Fig 1 shows the flux tower footprint. This was calculated considering a distance of approximately 100 times the instrument height above the zero plane displacement height, 2/3 of the canopy height. Then the estimated footprint radius) was $485 \mathrm{~m}$. Measurements started on April 2008 and ended on October 2010. The equipment consisted of a three-dimensional sonic anemometer (Model CSAT3, Campbell Scientific, Logan, UT USA), an open-path gas analyser to measure water vapor density (Model 7500, Licor, Lincoln, USA), a net radiometer (CNR2, Kipp\&Zonen, Delft, The Netherlands), three soil heat flux plates 
and thermocouples for soil temperature measurement (Model HFP01, Campbell Scientific, Logan, USA). All the equipment was fed by solar panels and data sampling frequency was $10 \mathrm{~Hz}$. The mean values were recorded every 30 minutes by 2 dataloggers; (CR1000, Campbell Scientific, for turbulent flows and CR10X Campbell Scientific, for radiation and soil heat flux) with data transmission via GSM modem. The data were processed to obtain 30-minute co-variances and averaged for each $24 \mathrm{~h}$, including nocturnal data, to obtain the daily averages. Corrections were applied to the latent heat (LE) to account for air density fluctuations due to heat and vapor transfer (Webb et al. 1980). Spectral transfer functions were applied to correct for frequency response on sensor separation, path length averaging and signal acquisition and processing time (Moore 1986). The soil heat flux was obtained by weighted averages of measured values from the flux plates at four different positions (under the canopy, in wetted and dry soil portions, and in the middle of the alleyway). Three soil thermistors, buried at $0.025 \mathrm{~m}$ depth close to the plates, allowed the calculation of the heat storage of the soil above the plates for correcting $\mathrm{G}$ by the combination method (Kimball and Jackson 1975). Half hourly and daily flux measurements of LE and H were corrected applying the Bowen ratio closure method (Twine at al. 2000), including the nighttime data.

Half hourly $\mathrm{ET}_{\mathrm{o}}$ was calculated using the FAO Penman-Monteith equation as in Allen et al. (1998) using the solar radiation, air temperature, air humidity, and wind speed values recorded in an automated weather station located near the orchard. The crop coefficient (i.e. ratio between actual ET to $\mathrm{ET}_{\mathrm{o}}$ ) was calculated each 30 minutes for the whole study period.

\subsection{SEBAL model calculations}


During the period when Eddy Covariance data were obtained (from 29/04/2008 to 28/09/2010), ten images from Landsat 5 satellite were used for SEBAL model calculations. In the study area, the images were free of clouds and no rain had occurred at least five days before image acquisition.

Acquisition time for all of the images was at 10:30 GMT. Images were geometrically, radiometrically and atmospherically corrected following the Remote Sensing Spanish National Plan protocols (Chuvieco and Hantson 2010). Surface temperature was calculated using the correction proposed by Cristobal et al. (2009) which takes into account air water vapor content and air temperature. Nevertheless, in SEBAL the nearsurface temperature gradients are an indexed function of radiometric surface temperature, thereby eliminating the need for absolutely accurate surface temperature (Allen et al. 2007b).

SEBAL estimates LE as a residual of the energy balance equation.

$\mathrm{LE}=\mathrm{R}_{\mathrm{n}}-\mathrm{G}-\mathrm{H}$

where LE is the latent energy consumed by evapotranspiration, $R_{n}$ is the net radiation, $G$ is the sensible heat flux conducted into the ground and $\mathrm{H}$ is sensible heat convected to the air, all in $\mathrm{W} \mathrm{m}^{-2} . \mathrm{R}_{\mathrm{n}}$ was calculated as in Allen et al. (2011). For G calculations, the empirical formula proposed by Bastiaanssen (2000) was adopted, which estimates the ratio $\mathrm{G} / \mathrm{R}_{\mathrm{n}}$ near midday as:

$$
\frac{G}{\mathrm{R}_{\mathrm{n}}}=\frac{\mathrm{T}_{\mathrm{s}}}{\alpha}\left(0.0038 \cdot \alpha+0.0074 \cdot \alpha^{2}\right) \cdot\left(1-0.98 \cdot N D V I^{4}\right)
$$

where $T_{\mathrm{s}}$ is the surface temperature $(\mathrm{K}), \alpha$ is the surface albedo and NDVI is the normalized difference vegetation index. $G$ is then calculated by multiplying $G R_{n}^{-1}$ by $\mathrm{R}_{\mathrm{n}}$.

$\mathrm{H}$ is estimated from an aerodynamic function: 
$H=\frac{\left(\rho \cdot c_{p} \cdot d T\right)}{r_{a h, 1,2}}$

where $\rho$ is air density $\left(\mathrm{kg} \mathrm{m}^{-3}\right), \mathrm{C}_{\mathrm{p}}$ is specific heat of air at constant pressure $\left(1004 \mathrm{~J} \cdot \mathrm{kg}^{-}\right.$ $\left.{ }^{1} \cdot \mathrm{K}^{-1}\right)$ and $\mathrm{r}_{\mathrm{ah} 1,2}$ is the aerodynamic resistance $\left(\mathrm{s} \mathrm{m}^{-1}\right)$ between two near-surface heights, $\mathrm{z}_{1}$ and $\mathrm{z}_{2}$ (generally 0.1 and $2 \mathrm{~m}$ above the zero-plane displacement height) computed as a function of the estimated aerodynamic roughness of the particular pixel. dT (K) is the temperature difference between the two heights $z_{1}$ and $z_{2}$ (Allen et al. 2011). dT is assumed to be linear in proportion to radiometric $T_{S}$ as Bastiaanssen (1995) empirically proved:

$$
d T=b+a \cdot T_{s}
$$

Since there are two unknown variables in (3), $d T$ and $r_{a h}$, an internal calibration process is performed. For that purpose, two extreme pixels, representing very dry and very wet agricultural surfaces, are selected as described in Allen et al. (2011).

In SEBAL, the cold pixel is a local water body, where $\mathrm{dT}=0$ is assumed, that means air temperature is equal to $\mathrm{T}_{\mathrm{s}}$ and $\mathrm{H}$ is expected to be zero. The dry end of the dT function is estimated for a selected "hot" pixel in the image where the soil is assumed to be dry enough that $\mathrm{LE}=0$ :

$$
d T_{\text {hot }}=\rho_{\text {airhot }} \cdot C_{p} \frac{\left(R_{n}-G\right)}{r_{\text {ahhot }}}
$$

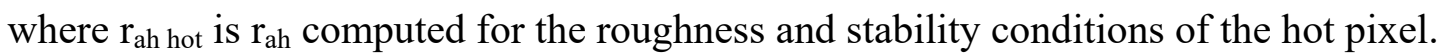
The values for $a$ and $b$ in Equation (4) are then estimated from these two pairs of dT and associated $\mathrm{T}_{\mathrm{s}}$ values.

In the present study, a water body was selected as cold pixel for all images. This option was selected instead of choosing a well-irrigated crop surface having full ground cover by vegetation as proposed by Allen et al. (2007b), because of: i) the presence of a 
nearby lake with sufficient size to clearly select cold pixels and ii) the absence of well watered fields with a full-cover crop of sufficient size near the study area. Hot pixels were selected in the abandoned and non-cropped agriculture plots without vegetation near the study area. Pixel selection was performed manually with the help of updated high resolution ortophotos. Dry pixels changed through the season if the presence of vegetation was detected by analyzing the NDVI value, making sure there was not vegetation.

\subsection{Momentum roughness length parameterization}

The aerodynamic resistance $\left(\mathrm{r}_{\mathrm{ah}}\right)$ depends on the momentum roughness length $\left(\mathrm{z}_{\mathrm{om}}\right)$ which is a measure of the drag form, air turbulence and skin friction for the layer of air that interacts with the surface (Campbell and Norman 1998). In general, the smaller the value specified for $z_{o m}$ the smaller the estimate for sensible heat flux, and thus the larger the ET estimate will be. $Z_{\mathrm{om}}$ has usually been empirically estimated from the average vegetation using the following equation (Brutsaert 1982)

$$
z_{\text {om }}=0.12 \cdot h
$$

where $\mathrm{h}$ is canopy height $(\mathrm{m})$.

SEB models based on SEBAL such as METRIC (Mapping Evapo-Transpiration with high Resolution and Internalized Calibration, Allen et al. 2011) estimate $\mathrm{z}_{\mathrm{om}}$ either using a land use map or according to the vegetation amount.

In the present experiment the Perrier function (Perrier 1982), which is based on LAI and tree canopy architecture for sparse trees, was used to estimate $\mathrm{z}_{\mathrm{om}}$. However, in order to obtain $\mathrm{h}$ for the citrus orchard, LIDAR (Light Detection and Ranging) data were used instead of employing tree density and canopy shape factors, as in Santos et al. (2012). LIDAR data were obtained from the Spanish National Plan for Remote Sensing and had 
a spatial resolution of 0.5 impacts per $\mathrm{m}^{2}$. Those LIDAR impacts classified as vegetation (ASPRS 2009) were selected and re-sampled to the same resolution of the Landsat images. In a $30 * 30 \mathrm{~m}^{2}$ resolution image, the maximum number of impacts on vegetation could be 30 . As the laser can impact in any part of the canopy, the value assigned to each pixel was done calculating the average height plus the standard deviation. Selecting the maximum height value as the re-sampling method would result in 5\% higher estimates of canopy height in comparison with the average height plus the standard deviation method.

The acquisition of LIDAR data was in July, 2009. Since no more LIDAR data were available for the three studied seasons and trees were mature, height crop was assumed constant throughout the study. The factor f was assumed to be 0.5 .

To contrast $z_{\text {om }}$ results, the Raupach's methodology (Raupach 1994) based on the frontal area index, which has been tested on a wide range of canopies (Verhoef et al. 1997), was applied to the study site and the results were compared with the Perrier function. As in SEBAL, $\mathrm{z}_{1}$ and $\mathrm{z}_{2}$ are heights above the zero-plane displacement plus the momentum roughness length, the zero-plane displacement was not estimated by any of the mentioned methods. Finally the standard procedure for $\mathrm{z}_{\mathrm{om}}$ estimation (i.e. $\mathrm{z}_{\mathrm{om}}=0.12 \mathrm{~h}$ ) was also used.

\subsection{Up-scaling instantaneous ET from instantaneous values to daily and 15-day values}

$\mathrm{ET}_{\text {inst }}$ has to be extrapolated to temporal frequency values useful for applications in irrigation scheduling and water resources management, such as daily or 15-day values (the Landsat revisit period is 16 days). The method that assumes self-preservation in the diurnal cycle of the energy budget, that is, that the evaporative fraction $[\mathrm{EF}=\mathrm{LE} /(\mathrm{Rn}-$ G)] remains constant over the day (Crago 1996), was not considered, given that flux 
tower data are required to calculate LE, a fact that reduces the possibilities of extrapolation. Three other methods were used for extrapolation.

\subsubsection{Constant Kc through the day}

The first approach used assumes that the instantaneous single crop coefficient $\left(\mathrm{Kc}_{\mathrm{inst}}\right)$ calculated from $\mathrm{ET}_{\text {inst }}$ and $\mathrm{ET}_{\mathrm{o}}$ is constant throughout the day (Allen et al. 2011).

$$
K c_{\text {inst }}=\frac{E T_{\text {inst }}}{E T_{\text {oinst }}}
$$

where $\mathrm{ET}_{\mathrm{inst}}$ is the estimated instantaneous rate (extrapolated to hourly data, $\mathrm{mm} \mathrm{h}^{-1}$ ) and $\mathrm{ET}_{\text {oinst }}$ is the reference evapotranspiration at the time of the snapshot $\left(\mathrm{mm} \mathrm{h}^{-1}\right)$.

Daily ET values obtained with this up-scaling procedure $\left(\mathrm{ET}_{\mathrm{ConstKc}}\right)$ are calculated as follows:

$$
\mathrm{ET}_{\text {ConstKc }}=\mathrm{ET}_{\text {odaily }} * \mathrm{~K}_{\text {Cinst }}
$$

where $\mathrm{ET}_{\text {odaily }}$ is the daily $\mathrm{ET}_{\mathrm{o}}$ obtained from a near meteorological station by the $\mathrm{FAO}$ method (Allen et al. 1998)

\subsubsection{Constant relation between ET and the observed solar radiation}

Since the assumption that $\mathrm{Kc}_{\text {inst }}$ is constant throughout the day might not hold true for certain orchard systems, Ryu et al. (2012) developed an alternative method based on assuming constancy in the ratio of ET to potential solar radiation $\left(\mathrm{R}_{\mathrm{so}}, \mathrm{W} \mathrm{m}^{-2}\right)$. Under this assumption, daily ET values $\left(\mathrm{ET}_{\text {SolRad }}\right)$ are calculated using the following formula where $\mathrm{SF}_{\mathrm{d}}(\mathrm{t})$ is the upscaling factor.

$$
E T_{\text {SolRad }}=\frac{1}{n} \sum_{d=1}^{n} \frac{1800 \cdot E T_{\text {inst }}\left(t_{d}\right)}{S F_{d}\left(t_{d}\right)}
$$


Van Niel et al. (2012) used observed fluxes as global solar radiation $\left(\mathrm{R}_{\mathrm{s}}\right)$ and available energy. As up-scaling factors, they tested $\mathrm{R}_{\mathrm{so}}$ and solar irradiance modeled fluxes obtained from a sine function. Their usefulness in converting the instantaneous ET to daily values on selected days over a 10 -year period from two sites of contrasting climate was tested. Their findings suggest that using $\mathrm{R}_{\mathrm{s}}$ was the best performing up-scaling factor in deriving daily ET. Cammalleri et al. (2013) compared four scaling methods using eddy covariance data collected at 12 AmeriFlux towers, sampling a wide range of climatic and land cover conditions. The methods tested used $\mathrm{R}_{\mathrm{s}}, \mathrm{R}_{\mathrm{so}}$, instantaneous ET and the evaporative fraction. Best results were obtained with $R_{s}$ due to absence of systematic biases. $\mathrm{R}_{\mathrm{so}}$ proved to be also reliable under near clear-sky conditions. The upscaling factor $\mathrm{SF}_{\mathrm{d}}(\mathrm{t})$ is calculated as follows:

$$
S F_{d}\left(t_{d}\right)=\frac{1800 \cdot E T_{\text {inst }}(t)}{\int_{d} E T_{\text {inst }}(t) d t} \approx \frac{1800 \cdot R_{s o}(t)}{\int_{d} R_{s o}(t) d t} \approx \frac{1800 \cdot R_{s}(t)}{\int_{d} R_{s}(t) d t}(10)
$$

Where $\mathrm{SF}_{\mathrm{d}}(\mathrm{t})$ is the up-scaling factor for a particular day (d) of the year and function of the time $\mathrm{t}$ of $\mathrm{ET}_{\text {inst }}, \mathrm{n}$ is the number of days considered for extrapolation and 1800 is the number of seconds in $30 \mathrm{~min}$.

$R_{s}$ was selected to be studied instead of $R_{s o} . R_{s}$ is a common parameter reported by meteorological stations, and gives information about the cloudiness when it is related with $\mathrm{R}_{\text {so }}$ (Allen et al. 1998), which can affect the ET up-scaling.

\subsubsection{Up-scaling of $E T_{\text {inst }}$ assisted by daily $K_{c}$ curves derived from eddy covariance} fluxes.

$\mathrm{Kc}_{\text {inst }}$ values from Eddy Covariance measurements, for each daily hour were obtained from data registered during the three irrigation seasons. Hourly corrected LE were obtained from the flux tower and hourly $\mathrm{ET}_{\mathrm{o}}$ from a nearby meteorological station. 
Results were grouped by months. As Fig 3 shows, $\mathrm{Kc}_{\text {inst }}$ curves exhibit a parabolic behavior. For polar-orbiting satellites like Landsat, only one point of the parabola can be calculated for each revisited period. This is not enough to interpolate the $\mathrm{Kc}_{\text {inst }}$ parabolic curves because at least three points are required. This method implies that previous research to characterize $\mathrm{Kc}_{\text {inst }}$ daily curves should have been conducted. From hourly $\mathrm{ET}_{\mathrm{o}}$ data, daily ET can be calculated as follows:

$$
E T_{24}=\sum_{i=0}^{i=n} K c_{i n s t_{-} i} \cdot E T_{o_{-} i}
$$

where $\mathrm{Kc}_{\mathrm{inst}_{-} \mathrm{i}}$ is the instantaneous ET for the fraction of a day $\mathrm{i}, \mathrm{ET}_{\mathrm{O}_{-} \mathrm{i}}$ is the reference evapotranspiration for the fraction of a day $\mathrm{i}$, and $\mathrm{n}$ is the total number of equal periods the day is divided.

Since $\mathrm{Kc}_{\text {inst }}$ always shows a parabolic trend, the estimated daily ET obtained from empirical curves can be improved with the data point from the image. Assuming $\mathrm{Kc}_{\text {inst }}$ curves are displaced a constant value for different days as Fig 4 illustrates, the up-scaled ET named $\left(\mathrm{ET}_{\text {ParabKc }}\right)$ can be improved by correcting the monthly mean $\mathrm{Kc}_{\text {inst }}$ curves with $\mathrm{Kc}_{\text {inst }}$ obtained from the image as follows:

$$
E T_{\text {ParaKc }}=\frac{K c_{\text {inst_SEBAL }}}{K c_{\text {inst }}} \sum_{i=0}^{i=n} K c_{\text {inst_i}} \cdot E T_{o_{-} i}
$$

where $\mathrm{Kc}_{\text {inst_SEBAL }}$ is the instantaneous ET fraction at the satellite overpass time calculated by SEBAL and $\mathrm{Kc}_{\text {inst }}$ is the instantaneous ET fraction estimated by means of previous experimental data, in this case obtained from the eddy covariance tower. In this way, estimated $\mathrm{Kc}_{\text {inst }}$ curves are displaced, resulting in a better fitting to the actual ET fraction for the time when the image is taken. This method implies that the obtained parabolic $\mathrm{Kc}_{\text {inst }}$ patterns can be used for daily ET up-scaling, without the need of having eddy covariance measurements. 
2.5.4 Up-scaling instantaneous ET from instantaneous values to daily and 15-day values

Given that Landsat revisit time is 16 days, it is important to obtain ET estimates for the days between consecutive snapshots. The three previously mentioned up-scaling methods (constant $\mathrm{K}_{\text {Cinst, }}$ global radiation and $\mathrm{Kc}$ parabolic curve) were then used to compute 15-day ET values.

\subsection{Rn correction}

$R_{n}$ is calculated by subtracting all outgoing radiant fluxes as depicted in Allen et al. (2007b). The incoming solar radiation $\left(\mathrm{R}_{\mathrm{s}}\right)$ can be obtained easily from a meteorological station instead of being estimated from $\mathrm{R}_{\text {so. }}$ The outgoing long-wave radiation is computed by estimating the surface emissivity using empirical formulas where LAI is computed. However, these types of equations have not yet been parameterized for citrus. To avoid and assess the error produced when estimating $R_{n}$, LE calculated by SEBAL was corrected as follows:

$$
L E_{-} S E B A L_{-} C=L E_{-} S E B A L \frac{R_{n_{-} E C}}{R_{n_{-} S E B A L}}
$$

\section{Results and discussion}

\subsection{Analysis of instantaneous fluxes}

SEBAL was applied to the ten scenes, calculating the instantaneous fluxes that comprise the surface budget energy equation $\mathrm{R}_{\mathrm{n} \_ \text {SEBAL }}, \mathrm{H} \_\mathrm{SEBAL}, \mathrm{G}$ _SEBAL and finally $L E$ _SEBAL as residual. The flux tower footprint was used as a mask to extract the average pixel values 
for each flux. These outcomes were compared to those obtained from the Eddy Covariance fluxes $\left(\mathrm{R}_{\mathrm{n}_{-} \mathrm{EC}}, \mathrm{H}_{-} \mathrm{EC}, \mathrm{G}_{-} \mathrm{EC}\right.$ and $\left.\mathrm{LE}_{-} \mathrm{EC}\right)$. In the ten days of acquisition of satellite images the Eddy Covariance closure ratio $\mathrm{CR}$ was calculated as ( $\left.\mathrm{LE}_{-} \mathrm{EC}+\mathrm{H}_{\mathrm{E}} \mathrm{EC}\right)$ / $\left(\mathrm{R}_{\mathrm{n}_{-} \mathrm{EC}}-\mathrm{G}_{-} \mathrm{EC}\right)$. The closure ratios shown in Table 2 were calculated for the 30 minutes when images were taken and for the whole day. The average of the closure ratios was 0.76 (30min fluxes at the time of images) and 0.72 (whole day).

The Perrier function was applied to the studied area and the mean $\mathrm{z}_{\mathrm{om}} / \mathrm{h}$ for the ten analyzed images was 0.21 . It contrasted with the obtained $\mathrm{z}_{\mathrm{om}} / \mathrm{h}$ with the Raupach method where the relation was 0.097 , assuming the coefficients reported in Tian et al. (2011). This value was lower than the general suggested value by Brutsaert (1982) where $\mathrm{z}_{\mathrm{om}} / \mathrm{h}=0.125$. The Relative Root Mean Square Error (rRMSE) comparing the H_SEBAL calculated by Perrier, Raupach and Brutsaert to $\mathrm{H}_{-} \mathrm{EC}$, were $0.10,0.14$ and 0.12 respectively. Fig 5 shows the comparison to $\mathrm{H}_{-} \mathrm{EC}$ for the ten studied dates. The Raupach method underestimated sensible heat for all dates. It suggests that formula coefficients should be parameterized for citrus. Using the Brutsaert method there was also a tendency to underestimate the sensible heat, but less than with the Raupach's method. Since the lowest rRMSE were obtained using the Perrier function, and there was no indication of any clear bias, the Perrier function was the selected method to calculate $\mathrm{z}_{\mathrm{om}}$. The comparisons of the fluxes measured by Eddy Covariance and estimated by SEBAL are summarized in Table 2 . The first flux estimated by SEBAL is $R_{n}$ which determines the available energy for the rest of the fluxes. As an average for the ten dates, rRMSE for $R_{n}$ was 0.07 . In addition, on only two dates $(15 / 08 / 2008$ and $12 / 10 / 2009)$ the error for $R_{n}$ determination was greater than 0.08 (Table 2 ). These results suggest that the SEBAL model determines fairly well the net radiation incident over a drip irrigated 
citrus orchard, under coastal Mediterranean conditions with general high air relative humidity due to the sea influence.

On the other hand, the mean RMSE and rRMSE for $\mathrm{G}$ were $28,7 \mathrm{~W} \mathrm{~m}^{-2}$ and 0.86 , which means that the adopted formula (Eq 2) does not estimate $\mathrm{G}$ in an acceptable way. The formula used for estimating $\mathrm{G}$ was developed by Bastiaanssen (2000) using data from cotton fields, often characterized by full ground and continuous canopy cover, very different aerodynamic conditions than in citrus orchards. On average for the 10 days studied, $G$ accounted for only $8 \%$ of $R_{n}$ at the time when images were taken. As Consoli et at. (2006b) and Villalobos et al (2009) reported in other energy balance studies in orchards; G was the quantitatively less important component of the energy balance. In any case, it seems that further research should be performed to develop a SEB method to better estimate $\mathrm{G}$ in conditions of drip irrigation and sparse trees as citrus orchards.. Other methods that take into account the soil thermal inertia should be analyzed (Murray and Verhoef, 2007a and 2007b). With the use of remotely sensed values of Ts and fractional soil surface coverage, which will be a function of leaf area index or NDVI, G predictions were improved for bare and sparsely vegetated soils.

Regarding $H$, the worst result was obtained on $12 / 10 / 2009$ when the rRMSE of $R_{n}$ was also high. This is due to the fact that when $R_{n}$ is overestimated in the selected "hot" pixel, like in the Eddy covariance footprint pixels, dT is also overestimated (see (5) for details). On the other days, the RE for $\mathrm{H}$ comparisons varied between 0.03 and 0.17 , indicating that $\mathrm{H}$ was reasonably well computed by the SEBAL model. After applying the correction (13), LE__SEBAL rRMSE was reduced from 0.09 to 0.06 implying that if $R_{n}$ estimation is improved, the re-parameterized SEBAL estimates LE more precisely. 
The comparisons between the $\mathrm{H}_{-}$SEBAL and LE_SEBAL_C predictions with the respective Eddy Covariance measured values are depicted in Fig 6. H_SEBAL was linearly related to the corresponding $\mathrm{H}_{\mathrm{EC}}$ data, with a coefficient of determination $\left(\mathrm{R}^{2}\right)$ of 0.87 . In the case of the LE_SEBAL_C, the correlation between SEBAL and Eddy Covariance measurements was less tight $\left(\mathrm{R}^{2}=0.71\right)$. This lower correlation is likely related to the smaller range of variability compared to $\mathrm{H}_{\text {_SEBAL}}$. As shown in Fig 6, SEBAL tended to slightly underestimate the LE values measured by Eddy Covariance. This was due to the fact that $\mathrm{G}_{\text {SSEBAL }}$ was overestimated and, despite its low contribution, the overestimation affects LE in the same amount, (since LE is calculated as the residual).

\subsection{Up-scaling of instantaneous evapotranspiration to daily values.From the} instantaneous ET, daily ET values were calculated using the three up-scaling procedures. The results obtained are shown in Table 3.

Under the assumption of constant $\mathrm{K}_{\mathrm{c}}$ along the entire day, good results were obtained for 5 dates which had an RE lower than 0.1 . However, for the rest of the dates the error was higher, reaching a maximum of 0.35 on $19 / 06 / 2008$. For those dates when $\mathrm{Kc}_{\mathrm{inst}}$ was similar to the estimated daily $\mathrm{K}_{\mathrm{c}}$ obtained by Eddy Covariance, there was good agreement between $\mathrm{ET}_{\text {ConstKc }}$ estimated by SEBAL and the ET values obtained by Eddy covariance. The large discrepancies obtained on the remaining days are presumably attributable to the considerable diurnal variation of $\mathrm{K}_{\mathrm{c}}$ values (Kriedemann 1986; Villalobos et al. 2009). For instance, in 19/06/2008 $\mathrm{K}_{\mathrm{c}}$ varied from a maximum value of around 1.0 registered early in the morning to a minimum value close to 0.39 reached at midday when the evaporative demand was high (Fig 7). Although the rRMSE was high using the constant $\mathrm{K}_{\text {cinst }}$ up-scaling method, there was a tight correlation $\left(\mathrm{R}^{2}=0.90\right)$ between the estimated ET and the measured values. Nonetheless, ET was 
underestimated because when the images were taken (10:30 GMT), the $\mathrm{K}_{\text {cinst }}$ was lower than the daily $\mathrm{k}_{\mathrm{c}}$.

Allen et al. (2007a), compared sugar beet ET measured in a weighting lysimeter with a SEB approach assuming constant $\mathrm{K}_{\mathrm{c}}$ throughout the day. For the eight dates of their experiment, an rRMSE of 0.3 was obtained. Eliminating a date whose error was 1.39, the rRMSE decreased to 0.14 . This error is slightly lower than that obtained in the present work, for the constant $\mathrm{K}_{\mathrm{c}}$ up-scaling method (0.18). On the other hand, Allen et al. (2007a), using this scaling method, obtained an $\mathrm{R}^{2}$ of 0.81 when comparing LE measurements from SEBAL and from lysimeter data. Similarly, Gonzalez-Dugo et al. (2009) obtained an $\mathrm{R}^{2}$ of 0.76 in rain-fed corn and soybean crops between METRIC estimates and Eddy Covariance. It seems, then, that when the crop height estimation and the momentum roughness length are parameterized, assuming constant $\mathrm{Kc}_{\text {inst }}$ for 1 -day extrapolation, SEBAL can yield similar results in terms of errors and correlation, both in vegetable crops and in citrus trees.

When using the global solar radiation up-scaling method to obtain the daily ET $\left(\mathrm{ET}_{\text {SolRad }}\right)$ there was a lower rRMSE than with the $\mathrm{ET}_{\text {ConstKc }}$ (Table 3). This is because the ratio of hourly to daily ET was found to be proportional to the ratio of hourly to daily global solar radiation (Fig 8). However, the correlation was worse compared to $\operatorname{ET}_{\text {ConstKc }}(0.7$ vs. 0.9$)$, meaning that it is more accurate but less robust, due to more variable biases.

When daily ET was up-scaled using the $\mathrm{K}_{\text {cinst }}$ parabolic curve procedure here developed, the rRMSE of the Eddy Covariance and SEBAL ET was 0.08. This high level of agreement between both ET measurements was obtained by displacing the monthly $\mathrm{K}_{\text {cinst }}$ curve using the factor $\mathrm{K}_{\text {cinst_SEBAL }} \cdot \mathrm{Kc}_{\text {inst }}{ }^{-1}$. For instance, for $13 / 09 / 2009$, the corrected $\mathrm{K}_{\text {cinst }}$ parabolic curve $\left(13 / 09 / 2010 \_\mathrm{Kc}_{\text {inst_SEBAL }}\right)$ is in closer agreement with the 
measured $\mathrm{K}_{\text {cinst }}$ curve obtained using Eddy Covariance than with the average daily $\mathrm{K}_{\text {cinst }}$ curve for September (Fig. 9). For 13/09/2010 the RE for the comparisons between the $\mathrm{ET}_{\text {ParbKc }}$ and that measured by Eddy Covariance ET was 0.01 (Table 3). When the monthly average $\mathrm{K}_{\text {cinst }}$ curve is used, the rRMSE between SEBAL and Eddy Covariance ET increases to 0.33 , highlighting the utility of the procedure here employed of displacing the parabolic curves. Indeed, using the $\mathrm{K}_{\text {cinst }}$ parabolic curves, up-scaling method allowed reduction of the error of the ET SEBAL determinations to values even lower than those previously reported by Allen et al (2007a) in sugar beet, assuming constant $\mathrm{K}_{\text {cinst }}$ along the day.

Regardless of the up-scaling methods used, the daily ET values obtained are also closely related with previous drip irrigated citrus ET data obtained in the same region by Castel (2000) using a weighting lysimeter where an empirical relationship between tree size and $\mathrm{K}_{\mathrm{c}}$ was obtained. In the present experiment, the average Kc value obtained using the $\mathrm{ET}_{\text {ParabKc }}$ upscaling method was 0.57 . The orchard had an average tree shaded area of $66 \%$ which corresponds to a Kc value of 0.63 when using the formula reported by Castel et al. (2000). As a consequence, it seems possible in the near future to use the reported SEBAL methodology to determine citrus ET for large orchards and therefore to schedule irrigation by matching water application to the remotely sensed ET data. This is an important outcome since it should be considered that Citrus is one of the most important crops in the world with an annual production in 2011 of almost 129 million tons (Faostat 2011). In Spain alone, there are more than 314.000 ha planted with citrus trees, of which around 292.000 ha are irrigated (MAGRAMA 2013).

\subsection{Up-scaling instantaneous evapotranspiration to 15-days ET values.}


Since the revisiting period of Landsat images is 16 days, $\mathrm{ET}_{\mathrm{inst}}$ was extrapolated to this time interval and compared to acquired data by eddy covariance. The three aforementioned up-scaling methods were used and results are shown in Table 4. When $\mathrm{K}_{\text {cinst }}$ is considered constant along the day for 15-day periods, ET was underestimated compared to Eddy Covariance. This is because the $\mathrm{K}_{\mathrm{cinst}}$ at image time acquisition was lower than the averaged 15 -day $\mathrm{K}_{\mathrm{c}}$ for most of the following 15 - day periods under analysis. Only for one period of time after day (24/07/2009) was ET overestimated (Table 4). The average rRMSE for all the image analysis was 0.36 , higher than the RE obtained for the daily up-scaling time period (Table 3) and for the instantaneous ET measurements (Table 2). This suggests that the assumption of constant $\mathrm{K}_{\text {cinst }}$ for citrus results in increasing errors in ET estimation when it is up-scaled to longer time periods.

Using the global solar radiation up-scaling factor, the 15-day ET was better estimated than simply using the constant $\mathrm{K}_{\text {cinst }}$ assumption (Table 4). Nevertheless, the rRMSE (0.19) was higher than for daily estimates (Table 3 ). This is because the ratio of hourly to daily global solar radiation and hourly to daily ET varied among the 15-day period after the image acquisition day. For instance, for day 15/08/2008, the 15-day ET estimates obtained using the global solar radiation up-scaling factor overestimated the ET determinations obtained by Eddy Covariance ( $\mathrm{RE}=0.33$, Table 4). In fact, for most of the days after $15 / 08 / 2008$, the ratio of hourly to daily solar radiation was lower than the measured hourly to daily ET ratio. This fact can be explained in part by the effect of cloudiness that can be measured by the relative shortwave radiation, the ratio of the solar (Rs) to the clear-sky solar radiation (Rso, Allen et al. 1998). Fig 10 shows the relative shortwave radiation at the satellite pass $\left(\mathrm{RsH} \mathrm{RsoH}^{-1}\right)$ and the whole day $(\mathrm{RsD}$ $\mathrm{RsoD}^{-1}$ ). For most of the days, the ratio of hourly to daily solar radiation was lower than 
the measured hourly to daily ET ratio. Only for those days where the difference of RsH $\mathrm{RsoH}^{-1}$ to $\mathrm{RsD} \mathrm{RsoD}^{-1}$ was larger than 0.1 , the radiation ratio was higher.

Fig 11 plots the ratio between the measured hourly to daily $\mathrm{ET}$ ratio $\left(\mathrm{ET}_{\mathrm{H}} \mathrm{ET}_{24 \mathrm{H}}{ }^{-1}\right)$ and hourly to daily solar radiation $\left(\mathrm{R}_{\mathrm{sH}} \mathrm{R}_{\mathrm{SD}}{ }^{-1}\right)$ vs. the hourly $\left(\mathrm{R}_{\mathrm{sH}} \mathrm{R}_{\mathrm{soH}}{ }^{-1}\right)$ to daily global solar radiation ratio $\left(\mathrm{R}_{\mathrm{SD}} \mathrm{R}_{\mathrm{soD}}{ }^{-1}\right)$ at the satellite pass and daily shortwave radiation. The $\mathrm{R}^{2}$ was 0.67 and it was statistically significant $(\mathrm{P}=0.04)$. This means that when $\mathrm{R}_{\mathrm{sH}} \mathrm{R}_{\mathrm{soH}}{ }^{-1}$ to $\mathrm{R}_{\mathrm{SD}} \mathrm{R}_{\mathrm{soD}}{ }^{-1}$ differs, i.e. the cloudiness at the satellite snapshot time was different from the daily cloudiness, the ratio between $\mathrm{ET}_{\mathrm{H}} \mathrm{ET}_{24 \mathrm{H}^{-1}}$ and $\mathrm{R}_{\mathrm{SH}} \mathrm{R}_{\mathrm{SD}}{ }^{-1}$ is affected. This relationship has a negative slope. That is, when the cloudiness at the satellite time was higher than day cloudiness $\left(\mathrm{R}_{\mathrm{sH}} \mathrm{R}_{\mathrm{soH}}{ }^{-1} / \mathrm{R}_{\mathrm{SD}} \mathrm{R}_{\mathrm{soD}}{ }^{-1}<1\right)$, the ratio $\mathrm{R}_{\mathrm{sH}} \mathrm{R}_{\mathrm{sD}}{ }^{-1}$ was lower than $\mathrm{ET}_{\mathrm{H}} \mathrm{ET}_{24 \mathrm{H}}{ }^{-1}$ that means that $\mathrm{ET}$ was underestimated for most of the days. The opposite happened when day cloudiness was higher than at the satellite time. For five upscaling dates, this relationship was significant (Table 4).

In order to improve this up-scaling method, Eq. (12) could be modified to include a correction factor, which accounts for the error due to the self-preservation assumption (Van Niel et al. 2012). Other factors such as vapor pressure deficit should be taken into account to explain the variation in the fluxes ratio along the up-scaling period. Finally, when using the parabolic $\mathrm{Kc}_{\text {inst }}$ curves the $\mathrm{rMSE}$ values for the 15 -day period were similar to those obtained when using the global solar radiation up-scaling procedure (0.18 vs. 0.19, Table 3). However ET values obtained were better correlated with the Eddy Covariance ones (0.53 vs. 0.12$)$, but the use of this up-scaling method requires that a previous study be conducted to obtain the monthly kc curves. Moreover, these curves are obtained for particular conditions that can vary over time. It should be highlighted that the SEBAL procedure here tested was validated in well watered trees. Theoretically SEBAL could also be used for obtaining ET under stress conditions, when 
approaches for estimating crop coefficients from remotely sensed vegetation indices are not valid. Under plant water stress conditions, SEBAL could be employed for adjusting the Kc versus vegetation index relationships. Other factors, such as the time step in the availability of cloud-free images with thermal band and adequate spatial resolution, should be studied to assess their application in certain areas. The temporal availability of satellite imagery with thermal band determines the success of the application. Also the spatial resolution of the images is crucial for application in the management of citrus areas where the orchard's size is small. Downscaling methods for remote sensing-based irrigation management should be assessed (Ha et al. 2012).

\section{Conclusions}

The SEBAL method was applied to a 400 ha farm of well irrigated mature citrus trees where energy fluxes were measured with Eddy Covariance. The momentum roughness length method that performed best was the Perrier function. To estimate crop height LIDAR data were used. Since LIDAR temporal resolution is low, empiric formulas relating crop height to some vegetation indices such as NDVI, LAI and ground cover should be studied.

The use of LIDAR with the Perrier function resulted in a re-parameterized SEBAL model to determine more precisely citrus orchard sensible heat fluxes. SEBAL also performed well for net radiation calculations, but not for soil heat flux estimations. Three up-scaling methods were tested to extrapolate instantaneous ET to daily and to 15-day periods. Good ET estimations were obtained for daily periods, which can be used for hydrology studies and also for irrigation management in large areas. For 15day estimates, the up-scaling methods based on $\mathrm{K}_{\text {cinst }}$ parabolic curves and on the global radiation are the best suited. However, an advantage of the latter method is that it does 
not require a previous estimation of the parabolic $\mathrm{K}_{\text {cinst }}$ curves, a feature that makes its implementation easier in other regions different from where the experiment was carried out. Indeed, for woody perennial crops such as citrus, with high coupling to the atmosphere and where the day-to-day ET to ETo relationships might change due to different VPD (Ballester et al. 2013), cloudiness (Van Niel et al. 2011) or other tree endogenous factors, it seems difficult to obtain precise mid-term (15 days) estimates of ET from a snapshot measurement taken in a given hour of a given day. Integration of this methodology with water balances will help to solve the aforementioned limitations (Allen and Pereira, 2009) and will improve the flux estimation when irrigation or precipitation has occurred in the hot pixels some days before the calculation (Allen et al 2007b).

\section{Acknowledgements}

This research was supported by funds from MINECO project Rideco-Consolider CSD2006-0067 and from Interreg IV Sudoe project “Telerieg”. This research is under the framework of the COST Action ES1106 "EURO-AGRIWAT”. Landsat Imagery was provided by the Spanish Remote Sensing Plan (PNT) and the European Space Agency. LIDAR-PNOA and ortophoto-PNOA were provided by (C) Instituto Geográfico Nacional 


\section{Bibliography}

Allen R G, Pereira LS, Raes D, Smith M (1998) Crop evapotranspiration. Guidelinesfor computing crop water requirements. FAO Irrigation and Drainage Paper No. 56, Rome, Italy.

Allen R G, Pereira L S (2009) Estimating crop coefficients from fraction of ground cover and height. Irri Sci 28,17-34

Allen R G, Tasumi M, Morse A, Trezza R, Wright J L, Bastiaanssen W, Kramber W, Lorite I J, Robison C W (2007a) Satellite-based energy balance for mapping evapotranspiration with internalized calibration (METRIC)—applications. J. Irrig. Drain. Eng. ASCE 133 (4), 395-406.

Allen R G, Tasumi M, Trezza R (2007b). Satellite-based energy balance for mapping evapotranspiration with internalized calibration (METRIC)—model. J. Irrig.Drain. Eng. ASCE 133 (4), 380-394.

Allen R G, Irmak A, Trezza R, Hendrickx J M H, Bastiaanssen W, Kjaersgaard J (2011) Satellite-based ET estimation in agriculture using SEBAL and METRIC. J. Hydrolog. Process. 25,4011-4027

Annandale J G, Stockle C O (1994) Fluctuation of crop evapotranspiration coefficients with weather. A sensitivity analysis. Irr. Sci. 15,1-7. 
ASPRS (2009) LAS specification. Version 1.3 - r10. The American Society for Photogrammetry \& Remote Sensing 5410 Grosvenor Lane, Suite 210 Bethesda, Maryland 20814-2160. USA

Ballester C, Castel J, Testi L, Intrigliolo D S, Castel J R (2013) Can heat-pulse sap flow measurements be used as continuous water stress indicators of citrus trees? Irrigat. Sci. DOI: $10.1007 / \mathrm{s} 00271-012-0386-5$.

Bastiaanssen W G M (1995) Regionalization of surface flux densities and moisture indicators in composite terrain: a remote sensing approach under clear skies in Mediterranean climates. PhD Diss., CIP Data Koninklijke Bibliotheek, Den Haag, the Netherlands; 273.

Bastiaanssen W G M, Menenti M, Feddes R A, Holstlag A A M (1998) A remote sensing surface energy balance algorithm for land (SEBAL). 1. Formulation. J. Hydrol. 212-213, 198-212.

Bastiaanssen W G M, Pelgrum H, Wang J, Ma Y, Moreno J, Roerink G J, van der Wal T (1998b) The surface energy balance algorithm for land (SEBAL): Part 2. Validation. J. Hydrol. 212-213, 213-229.

Bastiaanssen W G M (2000) SEBAL-based sensible and latent heat fluxes in the irrigated Gediz Basin Turkey. J. Hydrol. 229, 87-100. 
Berni J A J , Zarco-Tejada P J, Sepulcre-Cantó G, Fereres E,Villalobos F (2009)

Mapping canopy conductance and CWSI in olive orchards using high resolution thermal remote sensing imagery. Remote. Sens. Environ. 113,2380-2388.

Brutsaert W H (1982) Evaporation into the atmosphere. D. Reidel, Norwell, Mass., 199 pp.

Campos I, Neale C M U, Calera A, Balbontín C, González-Piqueras J. (2010) Assessing satellite-based basal crop coefficients for irrigated grapes (Vitis vinifera L.), Agric. Water. Manage. 98, 45-54.

Campbell G S, Norman J M (1998) An Introduction to Environmental Biophysics, Second Edition, Springer. ISBN 0-387-94937-2.

Cammalleri C, Anderson M C, Kustas W P (2013) Upscaling of evapotranspiration fluxes from instantaneous to daytime scales for thermal remote sensing applications, Hydrol. Earth Syst. Sci. Discuss., 10, 7325-7350.

Castel, J.R., 2000. Water use of developing citrus canopies in Valencia, Spain. Proceeding International Society Citriculture, IX Congress:223-226.

Chuvieco E, Hantson S (2010) Plan Nacional de Teledetección de Media Resolución. Procesamiento estándar de imágenes Landsat. Documento técnico de algoritmos a aplicar. Ministerio de fomento. Gobierno de España. 
Consoli S, D'urso G, Toscano A (2006a) Remote sensing to estimate ET-fluxes and the performance of an irrigation district in southern Italy. Agric. Water. Manage., 81, 295314.

Consoli S, Russo A, Snyder R, (2006b) Estimating evapotranspiration of orange orchards using surface renewal and remote sensing techniques. Earth Observation for Vegetation Monitoring and Water Management. AIP Conference proceedings 852, 185192.

Crago R D (1996) Conservation and variability of the evaporative fraction during the daytime. J. Hydrol. 180, 173-194.

Crago R D, Brutsaert W (1996) A daytime evaporation and the self-preserve of the evaporative fraction and the Bowen ratio. J. Hydrol. 178, 241-255.

Cristóbal J, Jiménez-Muñoz J C, Sobrino J A, Ninyerola M, Pons X (2009) Improvements in land surface temperature retrieval from the Landsat series thermal band using water vapor and air temperature. J. Geophys. Res 114, D08103.

FAOSTAT (2011). Online. Available from: http://faostat.fao.org/default.aspx

González-Dugo M P, Mateos L (2008) Spectral vegetation indices for benchmarking water productivity of irrigated cotton and sugarbeet crops. Agric. Water. Manage. 95, $48-58$ 
Gonzalez-Dugo M P, Neale C M U, Mateos L, Kustas W P, Prueger J H, Anderson M C, Li F (2009) A comparison of operational remote sensing-based models for estimating crop evapotranspiration. Agric. Forest Meteorol. 149, 1843-1853.

Ha W, Gowda P H, Howell T A (2012) A review of downscaling methods for remote sensing-based irrigation management: part I. Irrig Sci. doi.org/10.1007/s00271-0120340-6.

Kalma J D, MacVicar T R, McCabe M F (2008) Estimating land surface evaporation:a review of methods using remotely sensed surface temperature data. Surv. Geophys., doi:10.1007/s10712-008-9037-z.

Kimball B A, Jackson R D (1975) Soil-heat flux determination: a null-alignment method. Agr. Meteorol. 15, 1-9.

Kriedemann P E (1986) Tree water relations. Symposium on Physiology of Productivity of Subtropical and Tropical Tree Fruits. ISHS Acta Horticulturae 175.

Kustas W P, Norman J M (1996) Use of remote sensing for evapotranspiration monitoring over land surfaces. Hydrol. Sci. 41, 495-516.

Kustas W P, Li F, Jackson T J, Prueger J H, MacPherson J I, Wolde M (2004) Effects of remote sensing pixel resolution on modeled energy flux variability of croplands in Iowa. Remote Sens. Environ. 92,535-547. 
Liang S., Wang, K., Zhang X., Wild M (2010) Review on estimation of land surface radiation and energy budgets from ground measurement, remote sensing and model simulations. IEEE Journal of selected topics in applied earth observations and remote sensing, 3:225- 240 .

Jarvis P G (1985) Coupling of transpiration to the atmosphere in horticultural crops: the omega factor. Acta Horticult. 171, 187-205.

Jayanthi H, Neale C M U, Wright, J L (2007) Development and validation of canopy reflectance-based crop coefficient for potato. Agric. Water Manage. 88, 235-246.

MAGRAMA (2013). Anuario de estadística agrariadel Ministerio de agricultura y medio rural.

Mateos L, González-Dugo M P, Testi L, Villalobos F J (2013) Monitoring evapotranspiration of irrigated crops using crop coefficients derived from time series of satellite images. I. Method validation. Agric. Water Manage. http://dx.doi.org/10.1016/j.agwat.2012.11.005.

Minacapilli M, Agnese C, Blanda F, Cammalleri C, Ciraolo G, D'Urso G, Iovino M, Pumo D, Provenzano G, Rallo G (2009) Estimation of actual evapotranspiration of Mediterranean perennial crops by means of remote-sensing based surface energy balance models, Hydrol. Earth Syst. Sci., 13, 1061-1074.

Murray T, Verhoef A (2007a) Moving towards a more mechanistic approach in 
the determination of soil heat flux from remote measurements. I. A universal approach to calculate thermal inertia. Agric. Forest Meteorol. 147, 80-87.

Murray T, Verhoef A (2007b) Moving towards a more mechanistic approach in the determination of soil heat flux from remote measurements. II. Diurnal shape of soil heat flux. Agric. Forest Meteorol. 147, 88-97.

Perrier A (1982) Land surface processes: vegetation, in Eagelson P., ed., Land Surface Processes in Atmospheric General Circulation Models: Cambridge University Press, p. $395-448$.

Rana G, Katerji N (2000) Measurement and estimation of actual evapotranspiration in the field under Mediterranean climate: a review. Eur. J. Agron. 13 (2/3), 125-153.

Raupach, M. R. 1994. Simplified expressions for vegetation roughness length and zero-plane displacement as a function of canopy height and area index. BoundaryLayer Meteorology, 71(1-2), 211-216.

Ryu Y, Baldocchi D D, Black T A, Moors E J (2012) On the temporal upscaling of evapotranspiration from instantaneous remote sensing measurements to 8-day mean daily-sums. Agric. Forest Meteorol. 152, 212 - 222.

Samani Z, Bawazir A S, Bleiweiss M, Skaggs R, Longworth J, Tran V D, Pinon A (2009) Using remote sensing to evaluate the spatial variability of evapotranspiration and crop coefficient in the lower Rio Grande Valley, New Mexico. Irrig. Sci. 28,93-100 
Santos C, Lorite I, Allen R, Tasumi M (2012) Aerodynamic Parameterization of the Satellite-Based Energy Balance (METRIC) Model for ET Estimation in Rainfed Olive Orchards of Andalusia, Spain. Water Resources Management 26,11, 3267-3283.

Stanghellini C, Bosma A H, Gabriels P C J, Werkhoven C (1990) The water consumption of agricultural crops: how crop coefficients are affected by crop geometry and microclimate. Acta Hort. 278, 509-515. ian X, Li Z Y, van der Tol C, Su Z, Li X, He Q S (2011) Estimating zero-plane displacement height and aerodynamic roughness length using synthesis of LiDAR and SPOT-5 data. Remote Sensing of Environment, 115(9), 2330-2341

Twine T E, Kustas W P, Normanc J M, Cookd D R, Housere P R, Meyersf T P, Pruegerg J H, Starksh P J, Wesely M L (2000) Correcting eddy-covariance flux underestimates over a grassland. Agric. Forest Meteorol. 103, 229-317.

Verhoef A, McNaughton K G, Jacobs A F G (1997) A parameterization of momentum roughness length and displacement height for a wide range of canopy densities. Hydrology and Earth System Sciences, 1, 81-91.

Villalobos F J, Orgaz F, Testi L, Fereres E (2000) Measurement and modelling of evapotranspiration of olive(Olea europaea L.) orchards. Eur J Agron 13:155-163

Villalobos F J, Testi L, Moreno-Pérez M F (2009) Evaporation and canopy conductance of citrus orchards. Agric. Water. Manage. 96, 565-573. 
Van Niel T G, McVicar T R, Roderick M L, Van Dijk A I, Beringer J, Hutley L (2012)Upscaling latent heat flux for thermal remote sensing studies: Comparison of alternative approaches and correction of bias. J. Hydrol. 468-469,35-46.

Webb E K, Pearman G I, Leuning R (1980) Corrections of flux measurements for density effects due to heat and water vapour transfer. Q. J. R. Meteorol. Soc. 106, 85100. 


\section{List of Figures}

Fig 1 Location of the study area. The dashed circle delimits the flux tower footprint. Ortophoto resolution is $0.5 \times 0.5 \mathrm{~m}^{2}$.

Fig 2. Monthly Reference Evapotranspiration $\left(\mathrm{ET}_{\mathrm{o}}, \mathrm{mm}\right)$, Precipitation $(\mathrm{Pr}, \mathrm{mm})$ and daily average global radiation ( $\mathrm{Rs}, \mathrm{MJ} \mathrm{m}^{-2}$ ) during the experimental period, seasons 2008-2010.

Fig 3 Hourly average crop coefficient $\left(\mathrm{K}_{\mathrm{c}}\right)$ for April, May, June, July, August and September obtained from Eddy Covariance data from the three experimental seasons. Interpolation curves for each month were assumed as parabolic.

Fig 4 Interpolated instantaneous crop coefficient curves for Weeks 22, 23, 24, 25, 26 of 2008 obtained by averaging daily hourly values compared to interpolated crop coefficient curves for data across the entire month of May.

Fig 5 Comparison of sensible heat ( $\mathrm{H}_{-} \mathrm{SEBAL}_{\mathrm{L}}$ ) calculated by SEBAL using $\mathrm{z}_{\mathrm{om}}$ by Perrier, Raupach and Brutsaert methods ,to Sensible heat $\left(\mathrm{H}_{-} \mathrm{EC}\right)$ measured by Eddy Covariance. The solid line is the 1:1 line, while the rest of lines are the linear regressions.

Fig 6 Comparison of net radiation $\left(\mathrm{R}_{\mathrm{n}_{-} \mathrm{SEBAL}}\right)$, soil heat flux $\left(\mathrm{G}_{-}\right.$SEBAL $)$, sensible heat $\left(\mathrm{H}_{-}\right.$ SEBAL, ) and latent heat (LE_SEBALc, $)$ calculated by SEBAL to net radiation $\left(\mathrm{R}_{\mathrm{n}_{-} \mathrm{EC}}\right)$, soil heat flux $\left(\mathrm{G}_{-}\right.$EC $)$Sensible $\left(\mathrm{H}_{-} \mathrm{EC}\right)$ and latent heat (LE_EC) measured by Eddy Covariance. The solid line is the 1:1 line, while the dotted line is the linear regression . Fig 7. Diurnal variations during 19/06/2008 of A) Hourly reference evapotranspiration (ETo, mm) and hourly evapotranspiration (ET, mm). B) Hourly crop coefficients. 
Fig 8. Relationships between the ratio of hourly to daily $\mathrm{ET}\left(\mathrm{ET}_{\mathrm{H}} / \mathrm{ET}_{24 \mathrm{H}}\right)$ and the ratio between hourly and daily global solar radiation $\left(\mathrm{R}_{\mathrm{sH}} / \mathrm{R}_{\mathrm{SD}}\right)$. Data sets correspond to the April, June, August and September months. Each monthly data set is the average of three experimental seasons $(2008,2009$ and 2010).

Fig 9. Comparisons of crop coefficient (Kc) diurnal patterns for: 1) September $\left(\mathrm{Kc}_{\text {instSept }}\right)$ calculated using Eddy Covariance data 2$)$ hourly $\mathrm{Kc}_{\text {inst }}$ calculated using the SEBAL $\mathrm{Kc}_{\text {inst }}$ parabolic curve approach for day $13 / 09 / 2009$ and 3) $\mathrm{Kc}_{\text {inst }}$ curve obtained from Eddy covariance data for 13/09/2010.

Fig 10. Hourly to daily ET ratio $\left(\mathrm{ET}_{\mathrm{H}} \mathrm{ET}_{24 \mathrm{H}}{ }^{-1}\right)$ and the hourly to daily global solar radiation ratio $\left(\mathrm{R}_{\mathrm{sH}} \mathrm{R}_{\mathrm{soH}}{ }^{-1}\right)$ for $15 / 08 / 2008$ and the following 15 days (Primary axis). Relative shortwave radiation at the image acquisition time calculated as the ratio of hourly global solar radiation to the hourly clear-sky solar radiation $\left(\mathrm{R}_{\mathrm{sH}} \mathrm{R}_{\mathrm{soH}}{ }^{-1}\right)$, and daily relative shortwave radiation calculated as the ratio of daily global solar radiation to the daily clear-sky solar radiation $\left(\mathrm{R}_{\mathrm{sD}} \mathrm{R}_{\mathrm{soD}}{ }^{-1}\right)$.

Fig 11. Ratio of hourly to daily ET ratio $\left(\mathrm{ET}_{\mathrm{H}} \mathrm{ET}_{24 \mathrm{H}}{ }^{-1}\right)$ and the hourly to daily global solar radiation ratio $\left(\mathrm{R}_{\mathrm{SH}} \mathrm{R}_{\mathrm{SD}}{ }^{-1}\right)$ and Ratio of hourly global solar radiation to the hourly clear-sky solar radiation $\left(\mathrm{R}_{\mathrm{sH}} \mathrm{R}_{\mathrm{soH}}{ }^{-1}\right)$ at the image acquisition time to daily global solar radiation to the daily clear-sky solar radiation $\left(\mathrm{R}_{\mathrm{SD}} \mathrm{R}_{\mathrm{SOD}}{ }^{-1}\right)$ for $15 / 08 / 2008$ and for the following 15days.

\section{List of Tables}

Table 1 Reference evapotranspiration (ET $)$, actual crop evapotranspiration measured using Eddy Covariance $\left(\mathrm{ET}_{\mathrm{c}}\right)$, precipitation $\left(\mathrm{P}_{\mathrm{r}}\right)$ and irrigation volumes applied (I) for the three studied seasons in the case study. Units for all volumes in $\mathrm{mm}$. 
Table 2. Comparisons of the instantaneous fluxes estimated by SEBAL, Net Radiation $\left(\mathrm{Rn}_{-} \mathrm{SEBAL}\right)$, Sensible Heat $\left(\mathrm{H}_{-}\right.$SEBAL $)$, Ground Heat $\left(\mathrm{G}_{-}\right.$SEBAL $)$, Latent Heat (LE_SEBAL), and corrected Latent Heat (LE_SEBALc) with the corresponding values of Net Radiation $\left(\mathrm{Rn}_{-} \mathrm{EC}\right)$, Sensible Heat $\left(\mathrm{H}_{-} \mathrm{EC}\right)$, Ground Heat $\left(\mathrm{G}_{-} \mathrm{EC}\right)$ and Latent Heat (LE_EC $)$ measured with Eddy covariance. Units for all fluxes are $\mathrm{W} \mathrm{m}^{-2}$. Each pair of fluxes is compared by means of Relative Error (RE) and each RE column is summarized by the relative Root Mean Square Error (rRMSE) of the RE values. Path and Row are the code location for Landsat images. CR is the closure ratio of flux tower adjustment using the BowenRatio method.

Table 3 Comparison of daily ET values ( $\mathrm{mm}$ ) estimated by SEBAL with those measured by Eddy Covariance $\left(\mathrm{ET}_{\mathrm{EC}}\right)$ or. Three upscaling procedures were used to obtain daily ET values from the snapshot measurement at the image acquisition time: 1) Assuming constant $\mathrm{Kc}_{\text {inst }}\left(\mathrm{ET}_{\mathrm{ConstKc}}\right)$, 2) using global solar radiation as scaling factor $\left(\mathrm{ET}_{\text {SolRad }}\right)$ and 3$)$ using the parabolic Kc curves approach assuming $\left(\mathrm{ET}_{\text {ParabKc }}\right)$. The column RE shows the relative error between the daily ET determined by Eddy Covariance or SEBAL. rRMSE is relative Root Mean Square Error of the RE values and R2 is the coefficient of determination. Kc represents the daily crop coefficient obtained from Eddy Covariance data and the daily reference evapotranspiration (ETo). Table 4 Comparison of 15-day ET values (mm) estimated by SEBAL with those measured by Eddy Covariance $\left(\mathrm{ET}_{\mathrm{EC}}\right)$. Three upscaling procedures were used to obtain 15 days ET values from the snapshot measurement at the image acquisition time estimated by SEBAL 1) Assuming constant $\left.\mathrm{Kc}_{\text {inst }}\left(\mathrm{ET}_{\text {ConstKc }}\right), 2\right)$ using global solar radiation as scaling factor $\left(\mathrm{ET}_{\text {SolRad }}\right)$ and 3$)$ using the parabolic Kc curves approach $\left(\mathrm{ET}_{\text {ParabKc }}\right)$. The column RE shows the relative error between ET estimated by the different upscaling methods mentioned and $\mathrm{ET}_{\mathrm{EC}}$ for 15 days, $\mathrm{rRMSE}$ is the mean of the 
RE square values and $\mathrm{R}^{2}$ is the coefficient of determination. Kc represents the average 15 days crop coefficient value obtained from Eddy Covariance. $\mathrm{N}_{\text {DCSat }}$ means the number of days in the upscaling period that had a ratio of global solar radiation and clear-sky solar lower than 0.3 at the satellite revisit time and $\mathrm{N}_{\mathrm{DC}}$ the number of days that had a ratio lower than 0.3 for the whole day. $\mathrm{R}_{\text {Bias }}^{2}$ is the coefficient of determination of the bias of hourly to daily ET ratio and the hourly to daily global solar radiation ratio and bias of hourly global solar radiation to the hourly clear-sky solar radiation at the image acquisition to daily global solar radiation to the daily clear-sky solar radiation.* means if $\mathrm{R}^{2}{ }_{\text {Bias }}$ Was linear regression of biases were statically significant. 


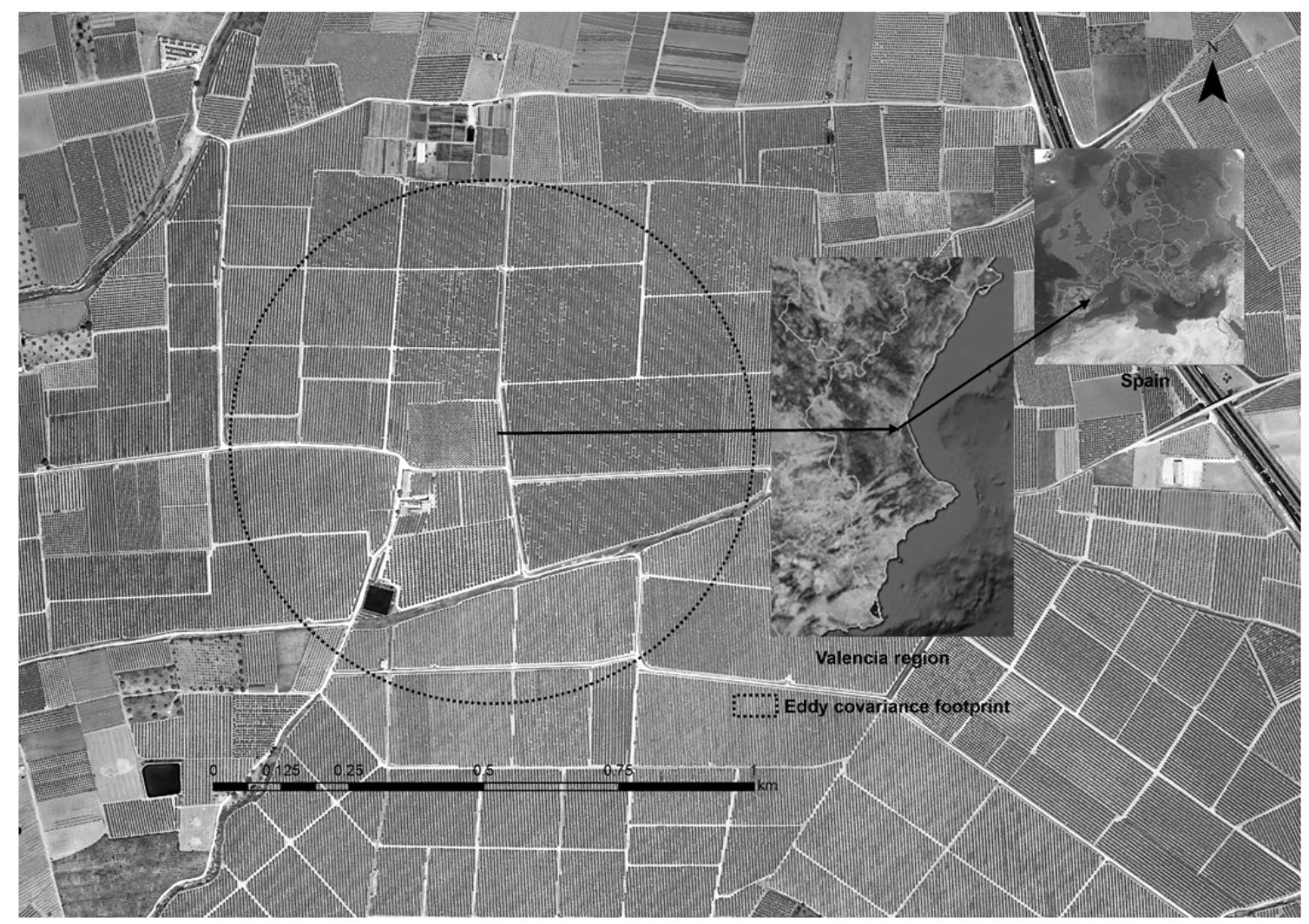

Fig 1 


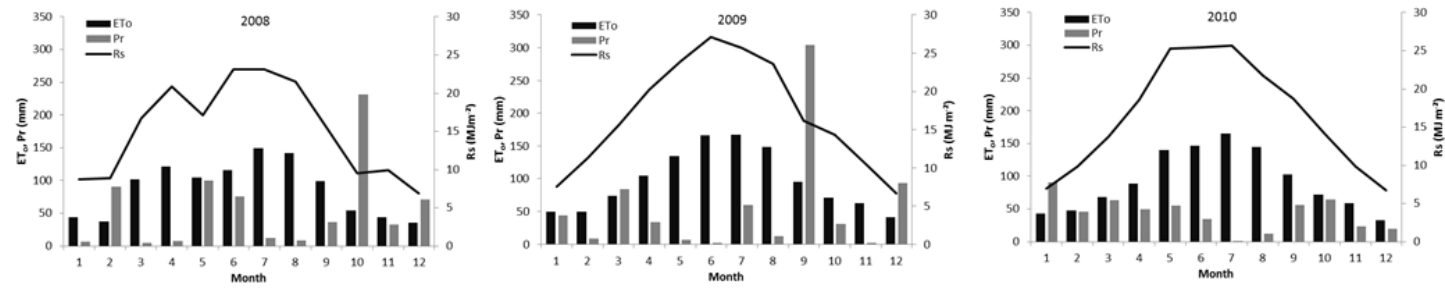

Fig 2 


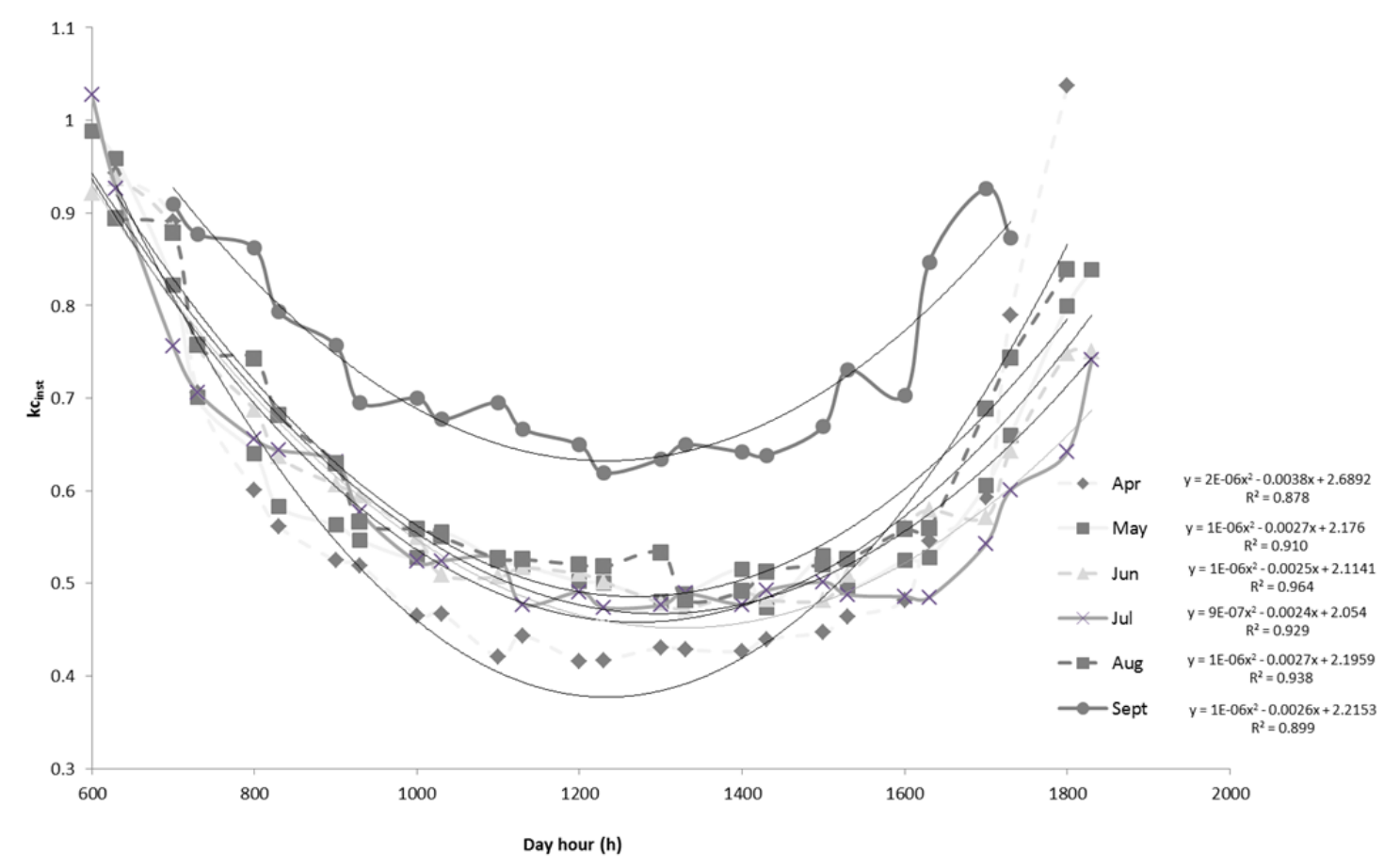

Fig 3 


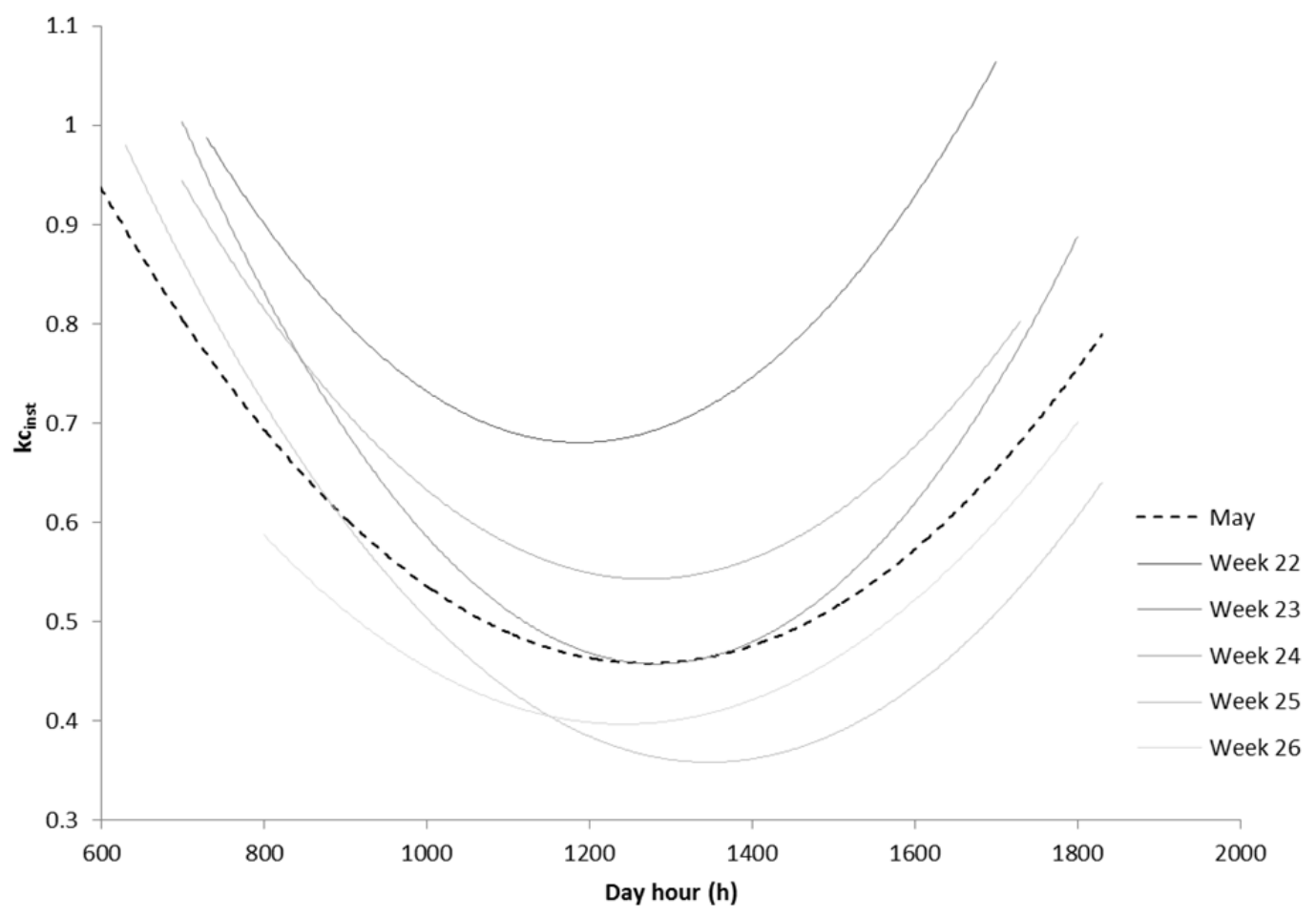

Fig 4 


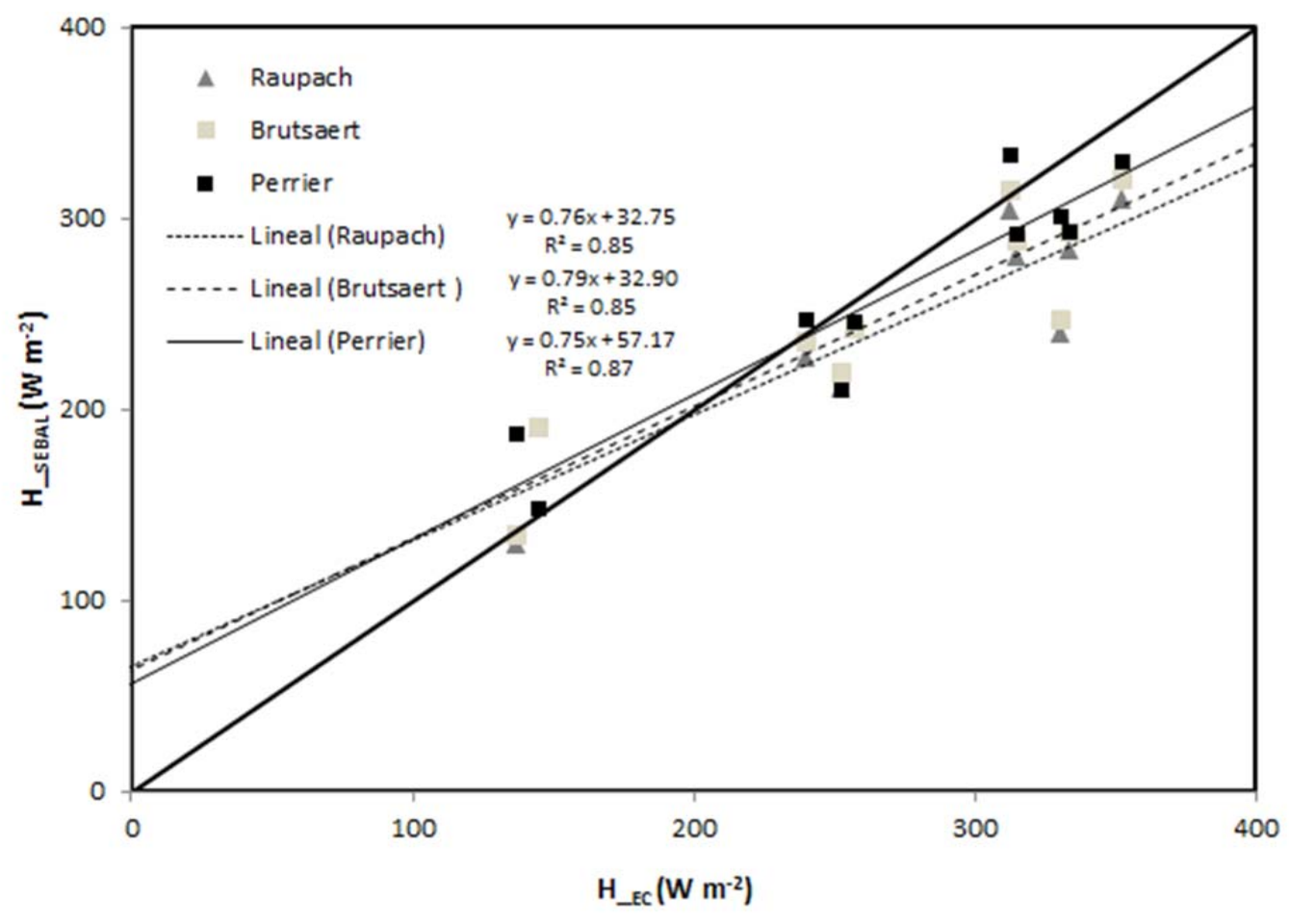

Fig 5 

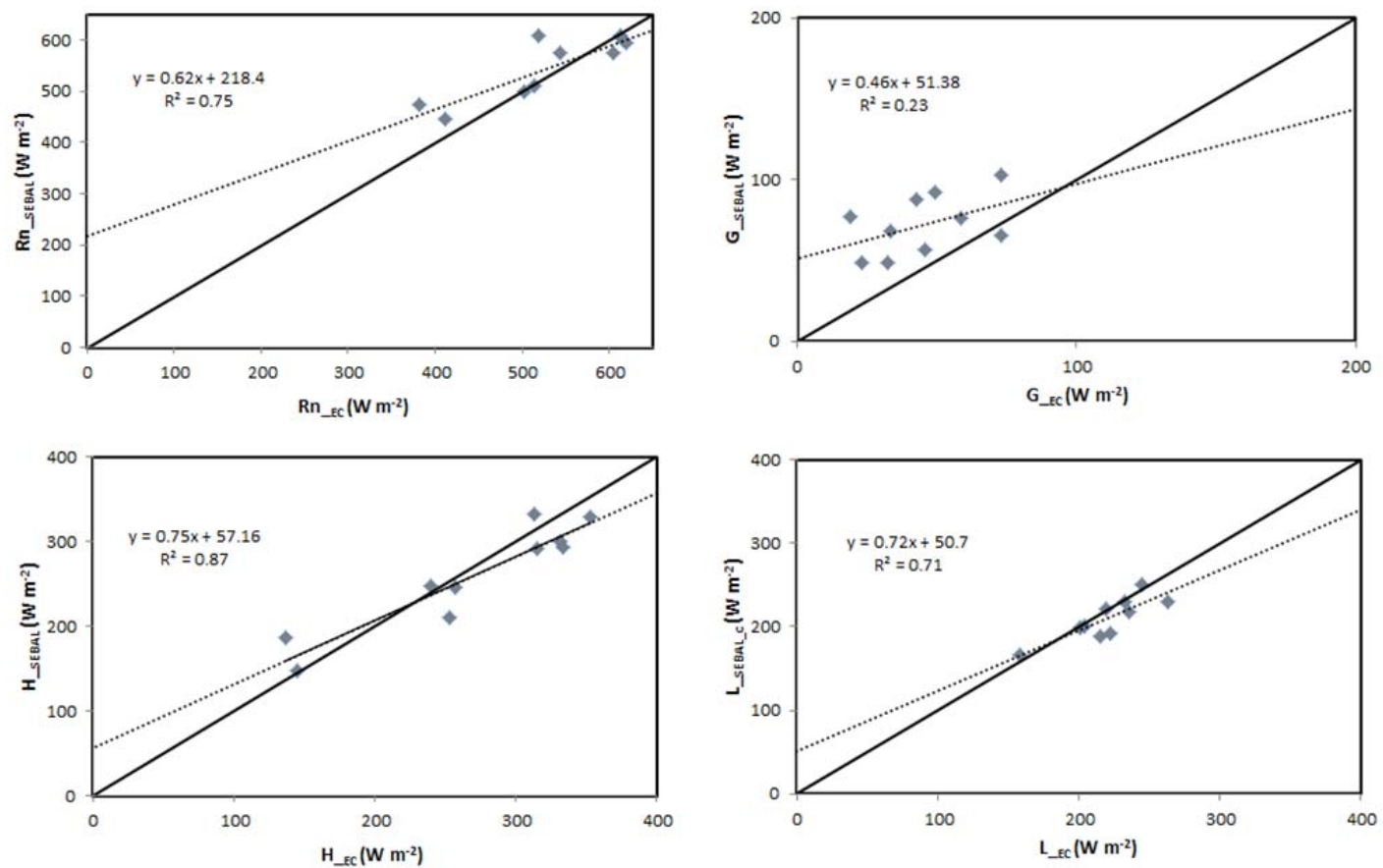

Fig 6 

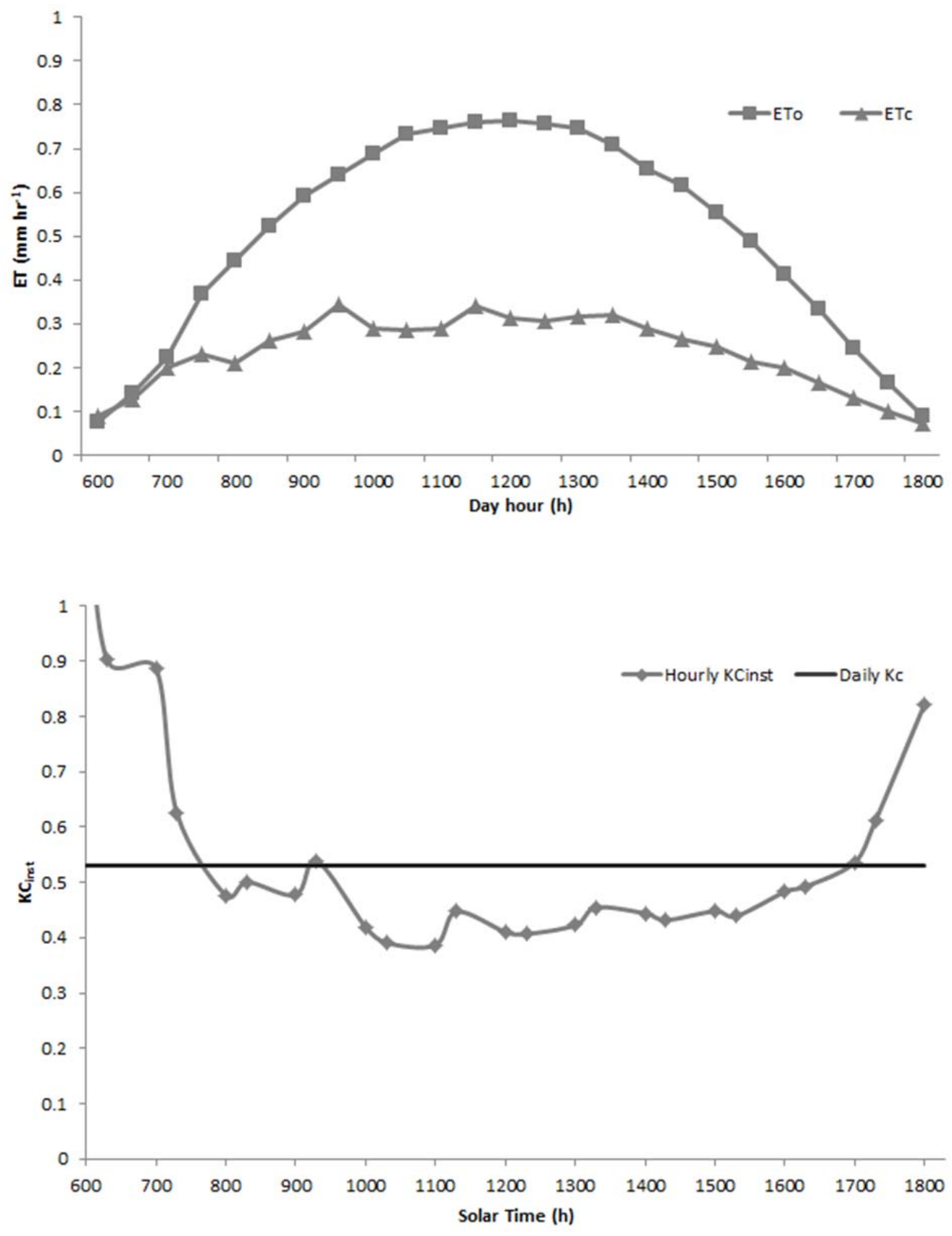

Fig 7 


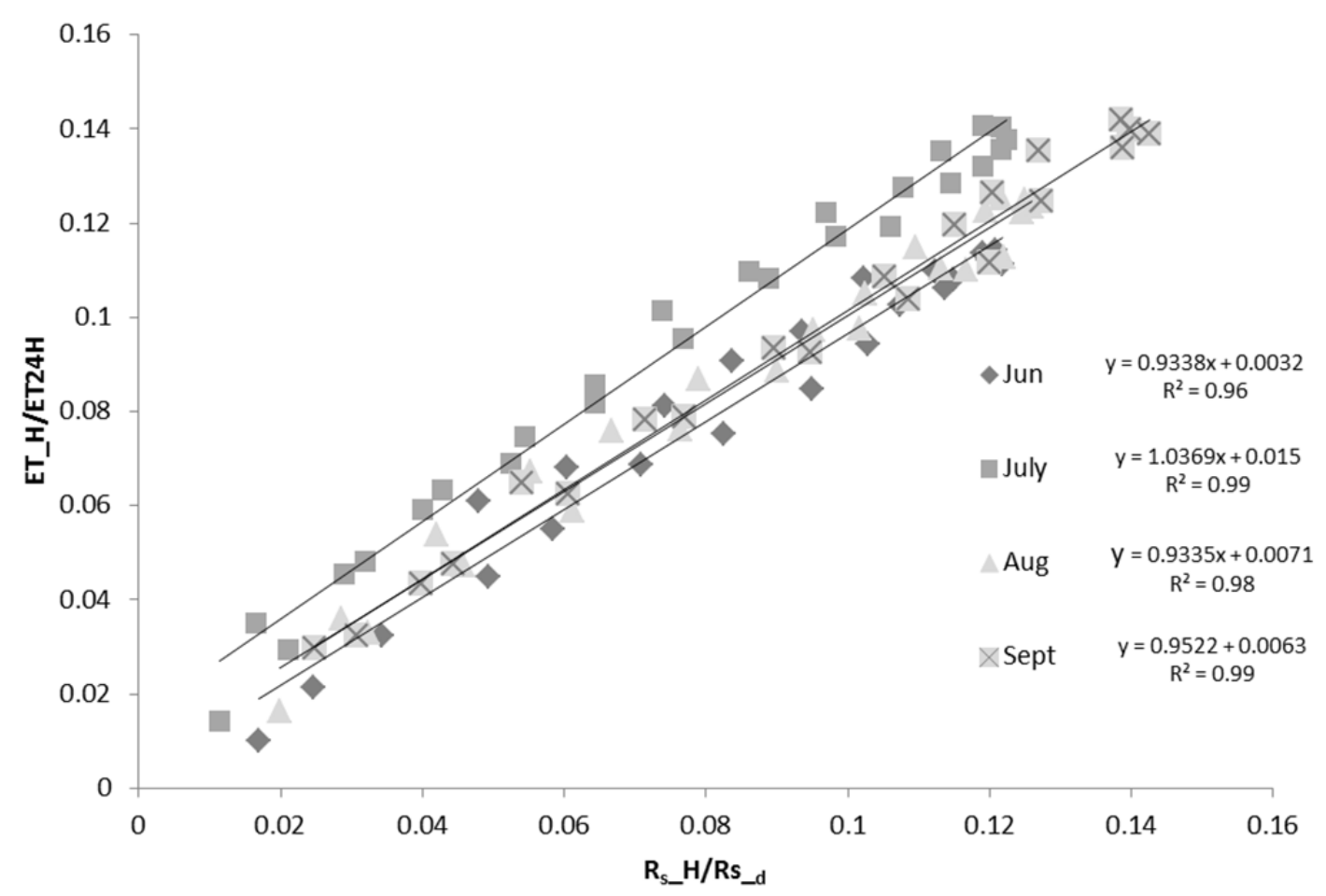

Fig 8 


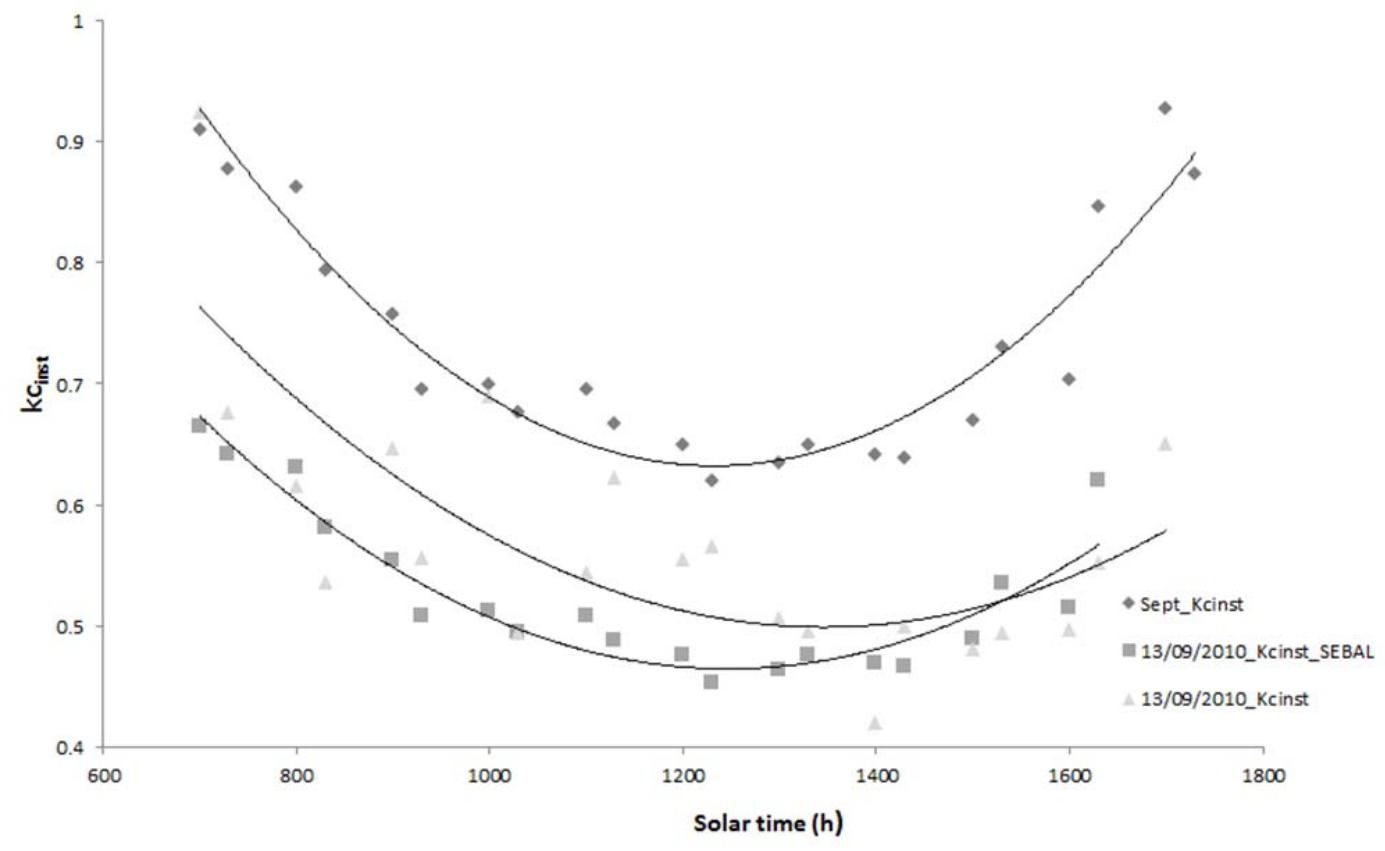

Fig 9 


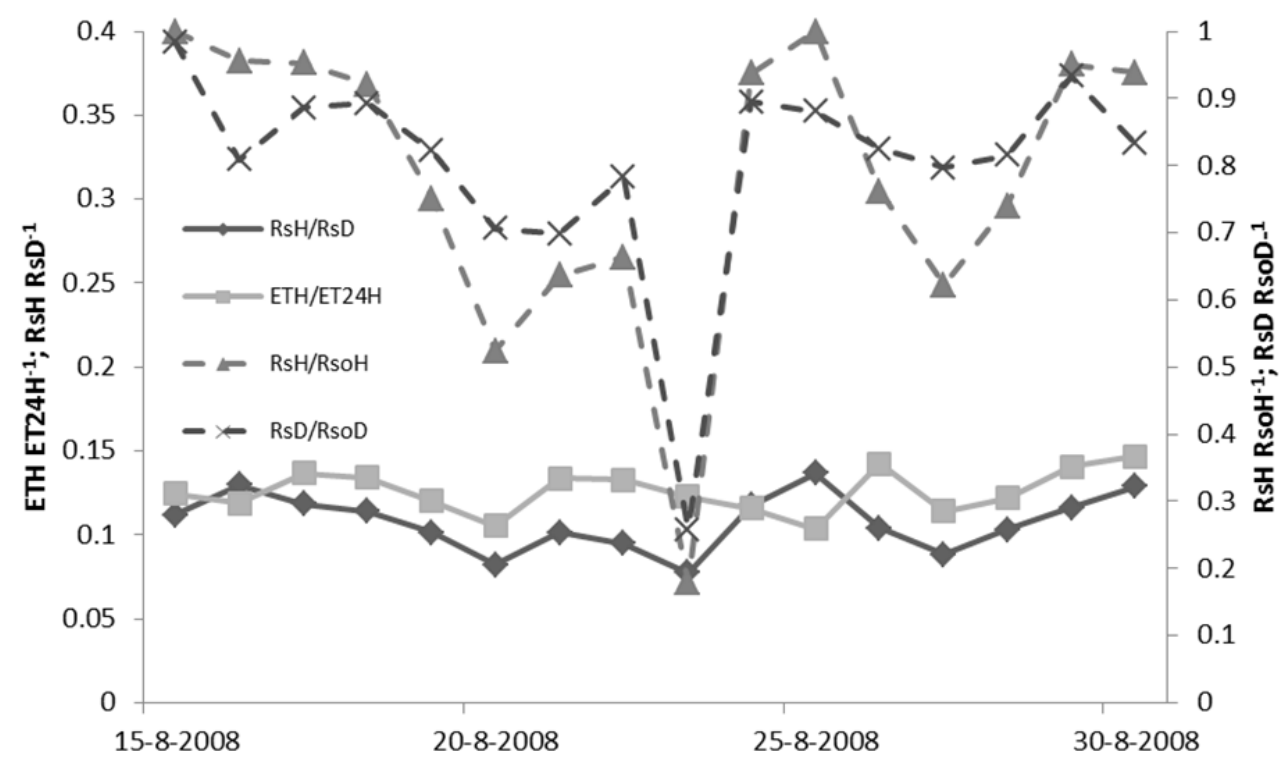

Fig 10 


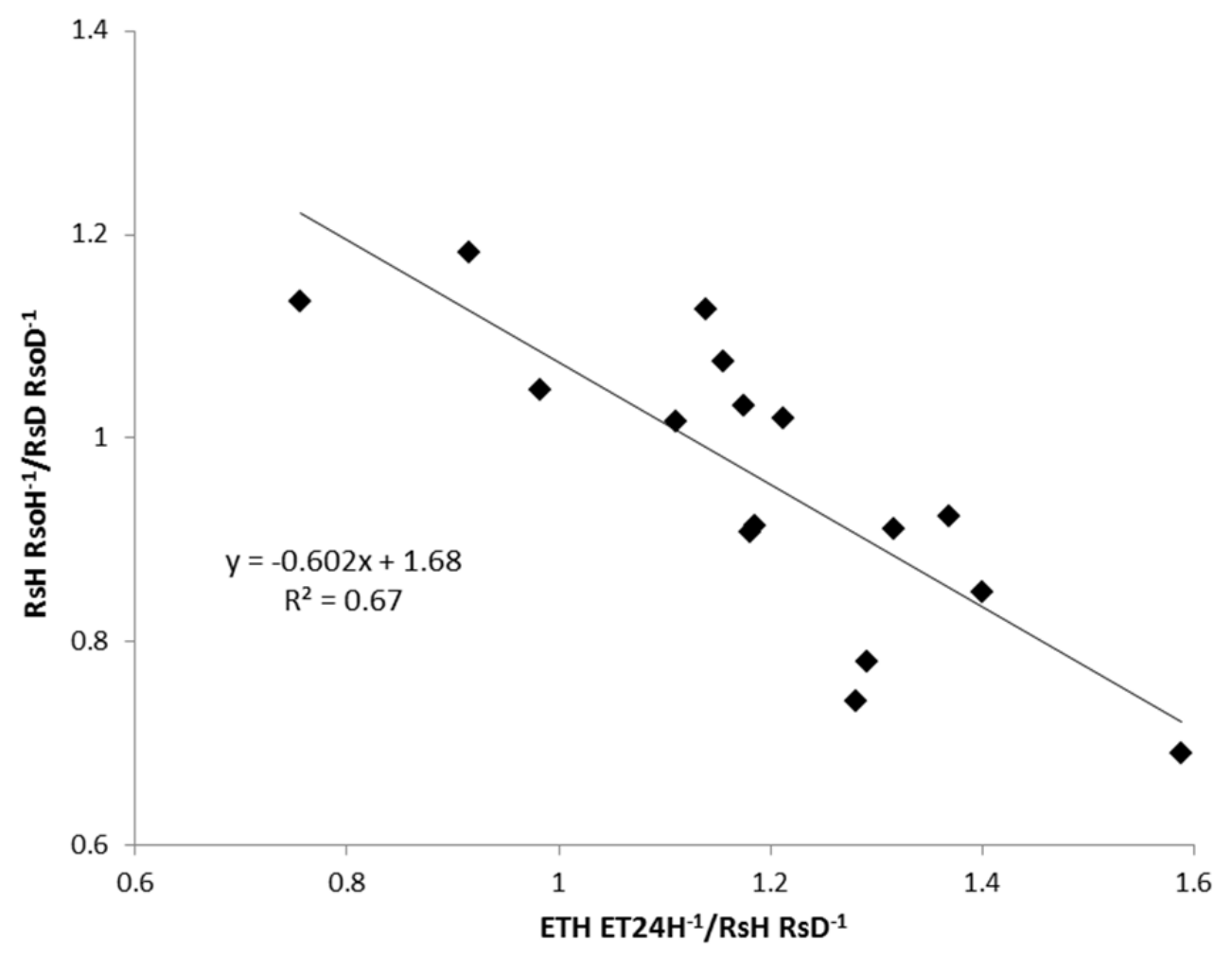

Fig 11 
Table 1 Reference evapotranspiration $\left(\mathrm{ET}_{\mathrm{o}}\right)$, actual crop evapotranspiration measured using Eddy Covariance $\left(\mathrm{ET}_{\mathrm{c}}\right)$, precipitation $\left(\mathrm{P}_{\mathrm{r}}\right)$ and irrigation volumes applied (I) for the three studied seasons in the case study. Units for all volumes in $\mathrm{mm}$.

\begin{tabular}{ccccc}
\hline Year & ETo & ETc & Pr & I \\
\hline 2008 & 748.7 & 383.2 & 649.0 & 353.9 \\
2009 & 1075.8 & 682.0 & 426.8 & 431.1 \\
2010 & 852.8 & 524.5 & 368.8 & 311.3 \\
\hline
\end{tabular}


Table 2. Comparisons of the instantaneous fluxes estimated by SEBAL, Net Radiation ( $\mathrm{Rn}$ _SEBAL $)$, Sensible Heat $\left(\mathrm{H}_{-}\right.$ SEBAL), Ground Heat (G_SEBAL), Latent Heat (LE_SEBAL), and corrected Latent Heat (LE_SEBALc) with the corresponding values of Net Radiation $\left(\mathrm{Rn}_{\_} \mathrm{EC}\right)$, Sensible Heat $\left(\mathrm{H}_{-} \mathrm{EC}\right)$, Ground Heat $\left(\mathrm{G}_{\_} \mathrm{EC}\right)$ and Latent Heat $\left(\mathrm{LE}_{\_} \mathrm{EC}\right)$ measured with Eddy covariance. Units for all fluxes are $\mathrm{W} \mathrm{m}^{-2}$. Each pair of fluxes is compared by means of Relative Error (RE) and each RE column is summarized by the relative Root Mean Square Error (rRMSE) of the RE values. Path and Row are the code location for Landsat images. CR is the closure ratio of flux tower adjustment using the Bowen-Ratio method.

\begin{tabular}{|c|c|c|c|c|c|c|c|c|c|c|c|c|c|c|c|c|}
\hline DATE & Path/Row & $\mathrm{Rn}_{E C}$ & $\mathrm{Rn}_{\text {SEEBAL. }}$ & $\mathrm{RE}$ & $\mathrm{G}_{\mathrm{EC}}$ & $\mathrm{G}_{\text {SEBBAL }}$ & $\mathrm{RE}$ & $\mathrm{H}_{-\mathrm{EC}}$ & $\mathrm{H}_{\text {SEBALL }}$ & $\mathrm{RE}$ & $\mathrm{LE}_{-\mathrm{EC}}$ & $\mathrm{LE}_{\text {SEBALL}}$ & $\mathrm{RE}$ & $\mathrm{LE}_{\text {SEBAL_C }}$ & $\overline{\mathrm{RE}}$ & $\overline{\mathrm{CR}}$ \\
\hline $19 / 06 / 08$ & 199,33 & 544 & 575 & 0.06 & 72.8 & 65.0 & -0.11 & 313 & 333 & 0.06 & 158 & 176 & 0.11 & 167 & 0.06 & 0.80 \\
\hline $15 / 08 / 08$ & 199,33 & 519 & 608 & 0.17 & 33.5 & 67.9 & 1.03 & 240 & 247 & 0.03 & 245 & 293 & 0.20 & 250 & 0.02 & 0.87 \\
\hline $24 / 07 / 09$ & 199,33 & 604 & 574 & -0.05 & 73.3 & 103.0 & 0.41 & 315 & 292 & -0.07 & 215 & 179 & -0.17 & 188 & -0.13 & 0.89 \\
\hline 03/09/09 & 198,33 & 514 & 510 & -0.01 & 42.5 & 87.8 & 1.07 & 253 & 210 & -0.17 & 219 & 220 & 0.00 & 221 & 0.01 & 0.81 \\
\hline 05/10/09 & 198,33 & 411 & 445 & 0.08 & 32.2 & 48.7 & 0.51 & 145 & 148 & 0.02 & 233 & 249 & 0.07 & 230 & -0.01 & 0.67 \\
\hline $12 / 10 / 09$ & 199,33 & 382 & 475 & 0.24 & 23.3 & 48.4 & 1.08 & 137 & 187 & 0.36 & 222 & 240 & 0.08 & 193 & -0.13 & 0.86 \\
\hline $24 / 05 / 10$ & 199,33 & 616 & 600 & -0.03 & 58.5 & 75.7 & 0.29 & 353 & 329 & -0.07 & 204 & 195 & -0.04 & 200 & -0.02 & 0.69 \\
\hline $11 / 07 / 10$ & 199,33 & 620 & 595 & -0.04 & 49.2 & 92.0 & 0.87 & 334 & 293 & -0.12 & 236 & 209 & -0.11 & 218 & -0.08 & 0.62 \\
\hline $27 / 07 / 10$ & 199,33 & 613 & 610 & 0.00 & 19.1 & 77.1 & 3.04 & 331 & 301 & -0.09 & 263 & 229 & -0.13 & 230 & -0.13 & 0.66 \\
\hline \multirow[t]{2}{*}{$13 / 09 / 10$} & 199,33 & 502 & 499 & -0.01 & 45.60 & 56.5 & 0.24 & 257 & 246 & -0.04 & 201 & 198 & -0.01 & 199 & -0.01 & 0.74 \\
\hline & & & rRMSE & 0.07 & & rRMSE & 0.86 & & rRMSE & 0.10 & & rRMSE & 0.09 & rRMSE & 0.06 & \\
\hline
\end{tabular}


Table 3 Comparison of daily ET values ( $\mathrm{mm})$ estimated by SEBAL with those measured by Eddy Covariance $\left(\mathrm{ET}_{\mathrm{EC}}\right)$ or. Three upscaling procedures were used to obtain daily ET values from the snapshot measurement at the image acquisition time: 1) Assuming constant $\left.\mathrm{Kc}_{\text {inst }}\left(\mathrm{ET}_{\mathrm{ConstKc}}\right), 2\right)$ using global solar radiation as scaling factor $\left(\mathrm{ET}_{\text {SolRad }}\right)$ and 3) using the parabolic Kc curves approach assuming $\left(\mathrm{ET}_{\text {ParabKc }}\right)$. The column RE shows the relative error between the daily ET determined by Eddy Covariance or SEBAL. rRMSE is relative Root Mean Square Error of the RE values and R2 is the coefficient of determination. Kc represents the daily crop coefficient obtained from Eddy Covariance data and the daily reference evapotranspiration (ETo).

\begin{tabular}{ccccccccccc}
\hline DATE & $\mathrm{Kc}_{\text {inst }}$ & $\mathrm{K}_{\mathrm{c}}$ & $\mathrm{ETo}$ & $\mathrm{ET}_{\mathrm{EC}}$ & $\mathrm{ET}_{\text {ConstKc }}$ & $\mathrm{RE}_{\text {ConstKc }}$ & $\mathrm{ET}_{\text {SolRad }}$ & $\mathrm{RE}_{\text {SolRad }}$ & $\mathrm{ET}_{\text {ParabKc }}$ & $\mathrm{RE}_{\text {Parakc }}$ \\
$19 / 06 / 2008$ & 0.34 & 0.53 & 5.36 & 2.83 & 1.85 & -0.35 & 2.48 & -0.12 & 2.44 & -0.14 \\
$15 / 08 / 2008$ & 0.59 & 0.56 & 6.2 & 3.48 & 3.68 & 0.06 & 3.70 & 0.06 & 3.52 & 0.01 \\
$24 / 07 / 2009$ & 0.44 & 0.46 & 7.39 & 3.39 & 3.25 & -0.04 & 3.18 & -0.06 & 2.99 & -0.12 \\
$03 / 09 / 2009$ & 0.54 & 0.57 & 5.93 & 3.37 & 3.22 & -0.04 & 3.22 & -0.04 & 2.92 & -0.13 \\
$05 / 10 / 2009$ & 0.6 & 0.88 & 2.69 & 2.37 & 1.61 & -0.32 & 2.74 & 0.16 & 2.32 & -0.02 \\
$12 / 10 / 2009$ & 0.53 & 0.79 & 2.62 & 2.07 & 1.38 & -0.33 & 2.35 & 0.14 & 2.27 & 0.10 \\
$24 / 05 / 2010$ & 0.44 & 0.57 & 5.27 & 3.03 & 2.3 & -0.24 & 3.17 & 0.05 & 2.91 & -0.04 \\
$11 / 07 / 2010$ & 0.42 & 0.53 & 5.73 & 3.02 & 2.43 & -0.19 & 3.54 & 0.02 & 3.07 & -0.03 \\
$27 / 07 / 2010$ & 0.59 & 0.6 & 5.68 & 3.44 & 3.36 & -0.02 & 4.03 & 0.17 & 3.94 & 0.15 \\
$13 / 09 / 2010$ & 0.5 & 0.62 & 4.12 & 2.55 & 2.04 & -0.2 & 2.68 & 0.05 & 2.53 & -0.01 \\
\hline
\end{tabular}


Table 4 Comparison of 15-day ET values ( $\mathrm{mm}$ ) estimated by SEBAL with those measured by Eddy Covariance $\left(\mathrm{ET}_{\mathrm{EC}}\right)$. Three upscaling procedures were used to obtain 15 days ET values from the snapshot measurement at the image acquisition time estimated by SEBAL 1) Assuming constant $\mathrm{Kc}_{\mathrm{inst}_{\mathrm{i}}}\left(\mathrm{ET}_{\mathrm{ConstKc}}\right)$, 2) using global solar radiation as scaling factor $\left(\mathrm{ET}_{\mathrm{SolRad}}\right)$ and 3$)$ using the parabolic Kc curves approach $\left(\mathrm{ET}_{\mathrm{Parab} \mathrm{c}}\right)$. The column $\mathrm{RE}$ shows the relative error between $\mathrm{ET}$ estimated by the different upscaling methods mentioned and $\mathrm{ET}_{\mathrm{EC}}$ for 15 days, $\mathrm{rRMSE}$ is the mean of the RE square values and $\mathrm{R}^{2}$ is the coefficient of determination. Kc represents the average 15 days crop coefficient value obtained from Eddy Covariance. $\mathrm{N}_{\mathrm{DCS} a t}$ means the number of days in the upscaling period that had a ratio of global solar radiation and clear-sky solar lower than 0.3 at the satellite revisit time and $\mathrm{N}_{\mathrm{DC}}$ the number of days that had a ratio lower than 0.3 for the whole day. $\mathrm{R}^{2}{ }_{\text {Bias }}$ is the coefficient of determination of the bias of hourly to daily ET ratio and the hourly to daily global solar radiation ratio and bias of hourly global solar radiation to the hourly clearsky solar radiation at the image acquisition to daily global solar radiation to the daily clear-sky solar radiation.* means if linear regression of biases were statically significant.

\begin{tabular}{|c|c|c|c|c|c|c|c|c|c|c|c|}
\hline DATE & Kc & $\mathrm{ET}_{\mathrm{EC}}$ & $\mathrm{ET}_{\text {ConstKc }}$ & $\mathrm{RE}_{\text {ConstKc }}$ & $\mathrm{ET}_{\text {SolRad }}$ & $\mathrm{RE}_{\text {SolRad }}$ & $\mathrm{ET}_{\text {ParabKc }}$ & $\mathrm{RE}_{\text {ParabKc }}$ & $\mathrm{N}_{\text {DCSat }}$ & $\mathrm{N}_{\mathrm{DC}}$ & $\mathrm{R}_{\text {Bias }}^{2}$ \\
\hline $19 / 06 / 2008$ & 0.58 & 45.84 & 27.12 & -0.41 & 34.92 & -0.24 & 30.91 & -0.33 & 0 & 0 & $0.54 *$ \\
\hline $15 / 08 / 2008$ & 0.74 & 44.64 & 36.92 & -0.17 & 59.71 & 0.33 & 42.79 & -0.04 & 1 & 1 & $0.55^{*}$ \\
\hline $24 / 07 / 2009$ & 0.52 & 38.74 & 45.03 & 0.16 & 48.80 & 0.26 & 39.62 & 0.02 & 0 & 0 & $0.53 *$ \\
\hline 03/09/2009 & 1.01 & 45.52 & 26.35 & -0.42 & 53.15 & 0.17 & 33.65 & -0.26 & 2 & 1 & $0.44 *$ \\
\hline $05 / 10 / 2009$ & 1.08 & 32.63 & 18.68 & -0.43 & 45.92 & 0.38 & 26.47 & -0.21 & 2 & 1 & 0.14 \\
\hline $12 / 10 / 2009$ & 1.13 & 33.51 & 17.91 & -0.47 & 36.31 & 0.12 & 24.54 & -0.28 & 2 & 1 & 0.02 \\
\hline $24 / 05 / 2010$ & 0.83 & 57.87 & 30.86 & -0.47 & 49.47 & -0.15 & 41.88 & -0.28 & 0 & 0 & 0.14 \\
\hline $11 / 07 / 2010$ & 0.74 & 53.7 & 31.97 & -0.4 & 50.77 & -0.04 & 54.78 & 0.02 & 0 & 0 & $0.54^{*}$ \\
\hline $27 / 07 / 2010$ & 0.73 & 50.3 & 40.97 & -0.19 & 53.11 & 0.06 & 50.39 & 0.00 & 0 & 0 & 0.05 \\
\hline \multirow[t]{3}{*}{$13 / 09 / 2010$} & 0.98 & 46.08 & 23.54 & -0.49 & 38.86 & -0.16 & 31.92 & -0.31 & 0 & 2 & 0.02 \\
\hline & & & rRMSE & 0.36 & rRMSE & 0.19 & rRMSE & 0.18 & & & \\
\hline & & & $\mathrm{R}^{2}$ & 0.15 & $\mathrm{R}^{2}$ & 0.12 & $\mathrm{R}^{2}$ & 0.53 & & & \\
\hline
\end{tabular}

